\title{
Predicting Breakage of High Aspect Ratio Particles in an Agitated Bed Using the Discrete Element Method
}

\author{
Y. Guo ${ }^{1}$, C. Wassgren ${ }^{2}$, B. Hancock ${ }^{3}$, W. Ketterhagen ${ }^{3}$, and J. Curtis ${ }^{1,4}$ \\ ${ }^{1}$ Department of Chemical Engineering, University of Florida, Gainesville, FL 32611, USA \\ ${ }^{2}$ School of Mechanical Engineering, Purdue University, West Lafayette, IN 47907, USA \\ ${ }^{3}$ Worldwide Research and Development, Pfizer, Inc., Groton, CT 06340, USA \\ ${ }^{4}$ College of Engineering, University of California, Davis, One Shields Ave, Davis, CA 95616, USA
}

\section{Abstract}

Predicting particle breakage is critical for the control of particle size in some bulk solids handling processes, such as those found in the pharmaceutical, food, consumer product, and mineral processing industries. This article presents a computational study of the breakage of high aspect ratio particles subject to mechanical agitation using the Discrete Element Method (DEM), in which a particle, represented by a string of bonded spheres, breaks at the center of a bond where the tensile or shear stress exceeds the material strength. The numerical model is validated using experimental results from the breakage of blackboard chalk sticks subject to uniaxial compression in a cylindrical container. The validated model is used to investigate particle breakage when agitated by rotating blades, which is encountered in a range of pharmaceutical processes, such as agitated filter drying, rotary tablet press feeding, and powder blending. The simulation results show that the breakage rate, that is the rate of particle size reduction (or the rate of fragment mass increase), increases as the applied pressure, impeller rotational speed, particle-particle friction, or particle-equipment friction increases. However, the extent of breakage per impeller revolution is independent of impeller rotational speed. Most importantly, it is found that the extent of particle breakage is a function of the work performed on the material, and the parameters in this function depend on the particleparticle and particle-wall friction coefficients. Large friction coefficients enable the input energy to break the particles more efficiently.

Keywords: Particle breakage; High aspect ratio particle; Agitated filter dryer; Discrete Element Method

\section{Introduction}


Particle breakage and degradation can be problematic in the processing of granular materials in pharmaceutical and consumer product industries, causing hazardous dust, handling problems in subsequent processes, and product quality problems. On the other hand, in mineral processing, large rocks need to be crushed into smaller ones for the extraction of mineral materials. In this process, the energy required for comminution needs to be predicted for proper equipment design. As a result, the prediction and control of particle breakage is crucial to many industries. Achieving this goal depends on the understanding of particle breakage in a bulk material and the effects of critical controlling parameters. From a single particle point of view, particle breakage is usually caused by the propagation of cracks, which is driven by stresses concentrated at the crack tips. Smaller particles are more difficult to break than larger ones because a small particle size can limit the length of cracks and allow little room for the stress distribution patterns to develop. As a result, smaller stress concentrations occur at the crack tips and larger external forces are required to drive crack propagation. Rather than single particle breakage, it is the overall particle size reduction and energy consumption of a bulk system that is of interest in most industrial situations. In these bulk systems, concurrent and continuous breakage of the particles depends on the particle properties and particle-particle and particle-equipment interactions.

A number of empirical models have been proposed to predict particle size reduction based on experimental data. However, these models have very specific applications (Rhodes, 1998). If the material or process is changed, the parameters in the models must be re-calibrated or may not be applicable. In recent years, computational modeling based on the Discrete Element Method (DEM) has been utilized to investigate particle breakage in many applications, such as in mineral processing (Weerasekara et al., 2013). The advantage of computational modeling of particle breakage is the ease with which material properties can be specified and operating processes adjusted. Nevertheless, high computational cost and the need for validated particle breakage models make model development challenging. The current work focuses primarily on this latter topic: the development and validation of a particle breakage model for high aspect ratio particles.

\subsection{Prediction of Particle Size Reduction}

From a population balance of a granular system (Rhodes, 1998), the rate of mass change of

$$
\frac{\mathrm{d} m_{i}}{\mathrm{~d} t}=\sum_{j=1}^{j=i-1}\left\{b(i, j) S_{j} m_{j}\right\}-S_{i} m_{i}
$$


where $m_{i}$ is the mass of particles of size interval $i$ and $S_{i}$ is the probability of particles of size interval $i$ being broken in unit time. The quantities $m_{j}$ and $S_{j}$ are for particles of size interval $j$. Assuming that the particle size decreases as the size interval level increases, the breakage distribution function $b(i, j)$ represents the fraction of breakage product from size interval $j$ that falls into size interval $i$. On the right hand side of Eq. (1), the first term represents the birth rate, which is the generation rate of new particles of size interval $i$ due to the breakage of larger particles while the second term represents the death rate, which is the breakage rate of particles of size interval $i$. In practice, the values of $S_{i}$ and $b(i, j)$ are determined from small scale tests and then Eq. (1) is used to predict the particle size distribution at a larger scale. Population balances have been widely employed for the prediction of particle breakage in various granular systems. For example, Sato et al. (2008) developed a population balance model for their experiments involving the breakage of high aspect ratio crystals in an agitated crystal bed in a thermostatic glass vessel. Grof et al. (2011) also developed a population balance model for needle-shaped crystals under uni-axial compaction, but determined the breakage probability and breakage distribution functions using a combination of computational and experimental methods.

Particle size reduction can also be caused by particle attrition, in which a small amount of mass is worn down from the particle surface. Neil and Bridgwater (1994) and Ghadiri et al. (2000) found that the extent of attrition is a function of the applied normal stress and shear strain and can be described by,

$$
M=k_{N}\left[\left(\frac{\sigma}{\sigma_{S C S}}\right) \Gamma^{\phi}\right]^{\beta},
$$

where $M$ is the mass of the lost material due to attrition, $\sigma$ is the normal stress, and $\Gamma$ is the shear strain. The side-crushing strength of the material, $\sigma_{S C S}$, is used to normalize $\sigma$. Three parameters $k_{N}, \beta$, and $\phi$ can be obtained by fitting the formula with experimental data. Using numerical modeling, Potapov and Campbell (1997) observed a different relationship between the extent of attrition, $M$, and the work exerted by an external force on the sheared particle 92 system, $W$,

$$
M=k_{w} W^{\alpha}
$$

where $k_{w}$ and $\alpha$ are fitting parameters.

\subsection{Computational Modeling of Particle Breakage}

Several DEM-based computational methods have been developed to simulate particle breakage 
the fragment spawning method or particle replacement method, and the particle attrition prediction method. These techniques are discussed in the following paragraphs.

In the bonded-particle method, a particle is formed by bonding a finite number of sub-particles, which can be spheres (Potyondy and Cundall, 2004; Grof et al. 2007), triangles (Potapov and Campbell, 1997), or polygons (Hosseininia and Mirghasemi, 2006). A particle breaks at the bond position where the stress exceeds the prescribed material strength. In the FDEM method (Munjiza, 2004; Ma et al., 2014), a particle is partitioned into a finite number of elements. Breakage occurs at the boundaries between the elements. A significant advantage of the bonded-particle method and FDEM method is that the stress distribution and fracture propagation within a particle can be modeled. The drawback of these two methods is that the size distribution after breakage is limited, considering that breakage has to occur at the bond positions or element boundaries. To increase the fragment size distribution, one may use additional sub-particles or elements to discretize a parent particle. However, the computational expense may be significantly increased. As a result, using the bonded-particle method is challenging for modeling an attrition process where only small fragments are broken off a particle.

To address the limited fragment size distribution and high computational cost in modeling stress and crack propagation, the fragment spawning method or particle replacement method was proposed (Kalman et al., 2009; Brosh et al., 2011; Bruchmüller et al., 2011). In this model, if the stress acting on a particle is smaller than the strength of the particle, a fatigue function is called and a reduced strength is assigned to the particle. Otherwise, if the operating stress is greater than the particle strength, a breakage function is called and a mother spherical particle is then replaced by child spheres having a wide size distribution. The generation of the child particles after breakage is governed by the specified fragment spawning, seeding, and interaction algorithms, which lead to an empirical size distribution obtained from experiments. Mass, momentum, and energy are all conserved in the replacement of the parent sphere with child spheres. This method has been successfully used to predict particle comminution in jet milling and pneumatic conveying (Brosh et al., 2011). Delaney et al. (2010) applied this approach to non-spherical particles breaking into many smaller non-spherical particles. In the fragments spawning or particle replacement method, the process of particle breakage is assumed to be transient, and the stress distribution and crack propagation within a particle are not resolved.

Hare et al. (2011) introduced a DEM approach for predicting the extent of particle attrition in agitated particle beds. In their method, the distributions of bulk stresses and strains in the bed are estimated from the DEM model. Next, the extent of particle attrition is predicted from an empirical correlation between attrition and particle-phase stresses and strains. This correlation 
can be obtained experimentally from shear cell tests (Neil \& Bridgewater, 1994). In this approach, the particle size change due to breakage and attrition is not considered directly in the DEM model, but the attrited mass is computed based on the DEM outputs (i.e., stresses and strains). Therefore, this particle attrition prediction method may be applicable only to a system with a small extent of breakage and negligible particle size change during the agitation process.

In their DEM simulations, Hua et al. (2015) investigated the internal load and moment distributions within rod-like particles in a blade-agitated mixer. The rod-like particles were modeled using sphero-cylinders, each of which has a cylindrical body and two hemispherical ends. With the assumption of small particle deformation, the stress distribution in a cross sectional area of a rod-like particle, which is perpendicular to the major axis of the particle, can be determined. They observed that the maximum absolute principal stress occurs along the particle circumference at the center-plane of the particle, indicating that high aspect ratio, rodlike particles are more likely to break in the center with the failure beginning from the circumference. This finding is consistent with previous results by Grof et al. (2007).

\subsection{Layout of This Article}

In this article, we use a bonded-particle method to model the breakage of high aspect ratio particles. Unlike the bonded-particle method employed in the work of Grof et al. (2007), for which the spheres are rigidly connected to form a non-deformable, needle-like particle, the current high aspect ratio particle model uses spheres that are connected using elastic bonds, allowing bending, twisting, and axial stretching deformation of an elongated rod-like particle (Guo et al., 2013b). A breakage criterion is implemented in the particle model so that the particle breaks when the tensile or shear stress in a bond exceeds the prescribed material strengths. The bonded-particle model used in this work is described in Sec. 2. In Sec. 3, we validate our numerical model by comparing simulation and experimental results for the breakage of blackboard chalk sticks under uni-axial compression in a cylindrical container. In the Sec. 4, the numerical model is applied to investigate the breakage of high aspect ratio particles in an agitated bed. This type of breakage phenomenon is observed in the crystallization and drying processes of active pharmaceutical ingredients (APIs). The effects of the stress environment, agitation rate, particle-particle friction, and particle-equipment friction on the extent of breakage are explored. Concluding remarks are made in Sec. 5.

\section{DEM Modeling of High Aspect Ratio Particle Breakage}

\subsection{Bonded-Particle Model}


The bonded-particle model used in this study has been described in our recent work (Guo et al., 2013b; Guo et al., 2015). In addition, a comprehensive verification of the mechanical responses of a single fiber, including bending, stretching/compressing, and twisting deformation, has been made by comparing the model with analytical solutions (Guo et al., 2013b). For convenience, the model is also summarized here.

A rod-like particle is formed by connecting a number of identical spheres in a straight line using virtual elastic bonds. Two ends of a single bond, which are fixed at the centers of two neighboring spheres, translate and rotate with the spheres. Thus, the relative movement of constituent spheres leads to the deformation of the bonds and also the fiber. A DEM simulation of the collision of two flexible fibers has been performed in our recent work, as shown in Figure 1. The bond forces/moments are generated and exerted on the spheres to resist the deformation. According to the bonded-particle model by Potyondy and Cundall (2004), the bond forces and moments can be calculated incrementally as follows:

$$
\begin{aligned}
& d F_{\mathrm{n}}^{\mathrm{b}}=K_{\mathrm{n}}^{\mathrm{b}} d \delta_{\mathrm{n}}^{\mathrm{b}}=\frac{E_{\mathrm{b}} A}{l_{\mathrm{b}}} d \delta_{\mathrm{n}}^{\mathrm{b}}=\frac{E_{\mathrm{b}} A}{l_{\mathrm{b}}} v_{\mathrm{n}}^{\mathrm{r}} d t \\
& d F_{\mathrm{t}}^{\mathrm{b}}=K_{\mathrm{t}}^{\mathrm{b}} d \delta_{\mathrm{t}}^{\mathrm{b}}=\frac{G_{\mathrm{b}} A}{l_{\mathrm{b}}} d \delta_{\mathrm{t}}^{\mathrm{b}}=\frac{G_{\mathrm{b}} A}{l_{\mathrm{b}}} v_{\mathrm{t}}^{\mathrm{r}} d t \\
& d M_{\mathrm{n}}^{\mathrm{b}}=K_{\mathrm{tor}}^{\mathrm{b}} d \theta_{\mathrm{n}}^{\mathrm{b}}=\frac{G_{\mathrm{b}} I \mathrm{p}}{l_{\mathrm{b}}} d \theta_{\mathrm{n}}^{\mathrm{b}}=\frac{G_{\mathrm{b}} I_{\mathrm{p}}}{l_{\mathrm{b}}} \omega_{\mathrm{n}}^{\mathrm{r}} d t \\
& d M_{\mathrm{t}}^{\mathrm{b}}=K_{\mathrm{ben}}^{\mathrm{b}} d \theta_{\mathrm{t}}^{\mathrm{b}}=\frac{E_{\mathrm{b}} I}{l_{\mathrm{b}}} d \theta_{\mathrm{t}}^{\mathrm{b}}=\frac{E_{\mathrm{b}} I}{l_{\mathrm{b}}} \omega_{\mathrm{t}}^{\mathrm{r}} d t
\end{aligned}
$$

in which $d F_{\mathrm{n}}^{\mathrm{b}}, d F_{\mathrm{t}}^{\mathrm{b}}, d M_{\mathrm{n}}^{\mathrm{b}}$, and $d M_{\mathrm{t}}^{\mathrm{b}}$ are the incremental bond normal force, shear force, torsional moment, and bending moment, respectively, and $d \delta_{\mathrm{n}}^{\mathrm{b}}, d \delta_{\mathrm{t}}^{\mathrm{b}}, d \theta_{\mathrm{n}}^{\mathrm{b}}$, and $d \theta_{\mathrm{t}}^{\mathrm{b}}$ are the incremental normal deformation, shear deformation, torsional (normal) angular deformation, and bending (tangential) angular deformation, respectively, of the bond. Thus, $K_{\mathrm{n}}^{\mathrm{b}}, K_{\mathrm{t}}^{\mathrm{b}}, K_{\mathrm{tor}}^{\mathrm{b}}$, and $K_{\text {ben }}^{\mathrm{b}}$ represent the normal, shear, torsional, and bending stiffnesses, respectively, of the bond. The cylindrical bond of Young's modulus $E_{\mathrm{b}}$ and shear modulus $G_{\mathrm{b}}$ has a radius $r_{\mathrm{b}}, \mathrm{a}$ length $l_{\mathrm{b}}$, a cross sectional area $A=\pi r_{\mathrm{b}}^{2}$, an area moment of inertia $I=\pi r_{\mathrm{b}}^{4} / 4$, and a polar area moment of inertia $I_{\mathrm{p}}=\pi r_{\mathrm{b}}^{4} / 2$. In the present model, the bond radius $r_{\mathrm{b}}$ is assumed to be 
197 the same as the constituent sphere radius $r_{\mathrm{s}}$, and the bond Young's modulus $E_{\mathrm{b}}$ and shear modulus $G_{\mathrm{b}}$ are correlated through the Poisson's ratio $\zeta: E_{\mathrm{b}}=2(1+\zeta) G_{\mathrm{b}}$. The virtual bond has no mass. The incremental bond deformation can be obtained from the product of the corresponding relative velocity between two bonded spheres $\left(v_{\mathrm{n}}^{\mathrm{r}}, v_{\mathrm{t}}^{\mathrm{r}}, \omega_{\mathrm{n}}^{\mathrm{r}}\right.$, or $\left.\omega_{\mathrm{t}}^{\mathrm{r}}\right)$ and the time 201 step $d t$.

202

The movement of individual constituent spheres in each fiber is governed by Newton's second 204

205

206 law of motion, i.e.,

207

in which $\boldsymbol{x}_{\mathrm{S}}$ and $\boldsymbol{\theta}_{\mathrm{S}}$ are the translational displacement and angular displacement, respectively,

of the sphere of mass $m_{\mathrm{s}}$ and moment of inertia $J_{\mathrm{s}}=\frac{2}{5} m_{s} r_{s}^{2}$. The translational motion of the sphere is driven by the contact force $\boldsymbol{F}^{\mathrm{c}}$ exerted by the spheres that are not bonded to it or come from a different composite particle, the bond force $\boldsymbol{F}^{\mathrm{b}}$ exerted by the bonds connecting to it, and the gravitational force $m_{\mathrm{s}} \boldsymbol{g}$. The bond force $\boldsymbol{F}^{\mathrm{b}}$ is calculated incrementally based on Eqs. (4) and (5). The moment $\boldsymbol{M}^{\mathrm{c}}$ arises from the tangential component of contact forces $\boldsymbol{F}^{\mathrm{c}}$, and $\boldsymbol{M}^{\mathrm{b}}$ represents the bond moment induced by the shearing, bending, and twisting deformation of the bond. A contact force $\boldsymbol{F}^{\mathrm{c}}$ can be decomposed into a normal force and a tangential force. The elastic normal force is computed based on the current normal overlap between two spheres using the Hertz model (Johnson, 1985). The tangential interaction consists of static and sliding friction processes. For static friction, the tangential force depends on the current normal force and the tangential loading path according to the Mindlin219 Deresiewicz theory (Thornton and Yin, 1991). When the tangential force exceeds the product of the friction coefficient $\mu$ and current normal contact force $F_{n}^{c}$, sliding friction occurs. The 221 tangential force during sliding is equal to $\mu F_{n}^{c}$, according to Coulombic sliding friction theory.

222 In Eq. (8), a contact damping force $\boldsymbol{F}_{\mathrm{d}}^{\mathrm{c}}$ is introduced to account for the energy dissipation when 223 two spheres collide. The normal and tangential contact damping forces can be written as, 


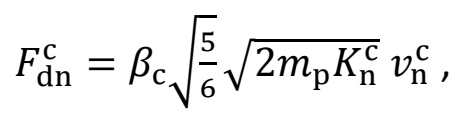

$225 \quad F_{\mathrm{dt}}^{\mathrm{c}}=\beta_{\mathrm{c}} \sqrt{\frac{5}{6}} \sqrt{2 m_{\mathrm{p}} K_{\mathrm{t}}^{\mathrm{c}}} v_{\mathrm{t}}^{\mathrm{c}}$,

226 in which $m_{\mathrm{p}}$ is the mass of a bonded particle or fiber. The symbols $K_{\mathrm{n}}^{\mathrm{c}}$ and $K_{\mathrm{t}}^{\mathrm{c}}$ represent the 227 contact normal stiffness and the contact tangential stiffness, respectively. The expressions of $228 K_{\mathrm{n}}^{\mathrm{c}}$ and $K_{\mathrm{t}}^{\mathrm{c}}$ are given by Thornton and Yin (1991) and are also summarized in Guo (2010). The 229 variables $v_{\mathrm{n}}^{\mathrm{c}}$ and $v_{\mathrm{t}}^{\mathrm{c}}$ represent the normal and tangential components, respectively, of the 230 relative velocity at the contact point. The contact damping coefficient $\beta_{\mathrm{c}}$ is related to the 231 coefficient of restitution $e$, which is defined as the ratio of the post-collisional to pre-collisional 232 relative velocity at the contact point. The correlation between $\beta_{\mathrm{c}}$ and coefficient of restitution $e$ 233 is provided in Guo et al. (2013a) and is expressed as,

$$
\beta_{c}=-\frac{\ln e}{\sqrt{\pi^{2}+\ln ^{2} e}} .
$$

235 In this study, the coefficients $\beta_{c}$ are chosen to give $e=0.95$ for particle-particle contacts and $e=$ 2360.90 for particle-wall contacts. In Eq. (9), $\boldsymbol{M}_{\mathrm{d}}^{\mathrm{c}}$ is the moment arising from the contact damping 237 force $\boldsymbol{F}_{\mathrm{d}}^{\mathrm{c}}$ :

$$
M_{\mathrm{d}}^{\mathrm{c}}=\boldsymbol{r} \times \boldsymbol{F}_{\mathrm{d}}^{\mathrm{c}}
$$

239 in which $\boldsymbol{r}$ is the vector from the center of the sphere to the contact point.

242 Analogous to contact damping, bond damping is proposed to take into account energy 243 dissipation due to elastic wave propagation within a particle. Thus, the bond damping forces 244 and moments are assumed to follow,

$$
\begin{aligned}
& F_{\mathrm{dn}}^{\mathrm{b}}=\beta_{\mathrm{b}} \sqrt{2 m_{s} K_{\mathrm{n}}^{\mathrm{b}}} v_{\mathrm{n}}^{\mathrm{r}}, \\
& F_{\mathrm{dt}}^{\mathrm{b}}=\beta_{\mathrm{b}} \sqrt{2 m_{s} K_{\mathrm{t}}^{\mathrm{b}}} v_{\mathrm{t}}^{\mathrm{r}}, \\
& M_{\mathrm{dn}}^{\mathrm{b}}=\beta_{\mathrm{b}} \sqrt{2 J_{s} K_{\mathrm{tor}}^{\mathrm{b}}} \omega_{\mathrm{n}}^{\mathrm{r}}, \\
& M_{\mathrm{dt}}^{\mathrm{b}}=\beta_{\mathrm{b}} \sqrt{2 J_{s} K_{\mathrm{ben}}^{\mathrm{b}}} \omega_{\mathrm{t}}^{\mathrm{r}} .
\end{aligned}
$$


The bond damping coefficient $\beta_{\mathrm{b}}$ varies in the range $0-1$ and determines the energy dissipation rate as the bond deforms. Similar to the contact damping coefficient $\beta_{\mathrm{c}}$, the bond damping coefficient is given by,

$$
\beta_{\mathrm{b}}=-\frac{\ln e_{\mathrm{b}}}{\sqrt{\pi^{2}+\ln ^{2} e_{\mathrm{b}}}}
$$

in which $e_{\mathrm{b}}$ reflects the reduction in the relative velocity between two bonded spheres due to the bond damping. In this study, the values of $e_{\mathrm{b}}$ were assigned to be $0.88,0.76$, and 0.64 to give $\beta_{\mathrm{b}}$ values of 4.20 e-2, 8.87 e-2, and 1.41 e-1, respectively. The bond damping force $\boldsymbol{F}_{\mathrm{d}}^{\mathrm{b}}$ and bond damping moment $\boldsymbol{M}_{\mathrm{d}}^{\mathrm{b}}$ (based on Eqs. (12)-(15)) are inputted to Eqs. (8) and (9).

\subsection{Breakage Criterion}

In this work, the breakage of a particle is modeled as the failure of bonds and the disconnection of two bonded constituent spheres. As proposed by Potyondy and Cundall (2004), a bond fails when the maximum normal stress, $\sigma_{\text {max }}^{\mathrm{b}}$, or the maximum shear stress, $\tau_{\text {max }}^{\mathrm{b}}$, exceeds the corresponding tensile strength, $\sigma_{\text {ten }}$, or shear strength, $\tau_{\text {sh }}$,

$$
\begin{aligned}
\sigma_{\max }^{\mathrm{b}} & =\frac{F_{\mathrm{n}}^{\mathrm{b}}}{A}+\frac{\left|M_{\mathrm{t}}^{\mathrm{b}}\right| r_{\mathrm{b}}}{I}>\sigma_{\mathrm{ten}} \\
\text { or } \quad \tau_{\max }^{\mathrm{b}} & =\frac{\left|F_{\mathrm{t}}^{\mathrm{b}}\right|}{A}+\frac{\left|M_{\mathrm{n}}^{\mathrm{b}}\right| r_{\mathrm{b}}}{I_{\mathrm{p}}}>\tau_{\mathrm{sh}} .
\end{aligned}
$$

\section{Validation of Particle Breakage Model by Uniaxial Compression Tests}

Validation of the implemented particle breakage model was examined by conducting experiments and performing numerical simulations of particle breakage under uniaxial compression. The uniaxial compression experiment is shown in Figure 2. A bed of 300 identical blackboard chalks was gently deposited in a cylindrical container of diameter $200 \mathrm{~mm}$. The cylindrical chalks have a length of $L=80 \mathrm{~mm}$ and a diameter of $D=10 \mathrm{~mm}$. Using a three point bending test, the Young's modulus of the chalk sticks was measured as $E=527.6 \pm 18.1 \mathrm{MPa}$ and the tensile strength as $\sigma_{\text {ten }}=3.99 \pm 0.06 \mathrm{MPa}$. The experimental setup and procedure for performing three-point bending tests are provided in the supplementary material for this article. The shear strength is assumed to be the same as the tensile strength: $\tau_{\text {sh }}=\sigma_{\text {ten }}$. Five tests were performed for this measurement. The friction coefficient between the chalks was measured as $\mu_{\mathrm{pp}}=0.624 \pm 0.024$ (obtained from six tests) using the "tilted plane" method in 
which the angle of the tilted plane from the horizontal is recorded when a chalk starts sliding on the surface of a pack of chalks fixed on the top of the plane. The mass of a chalk stick is measured using a scale and the volume is computed from its diameter and length. The chalk density, which is equal to the mass divided by the volume, was measured as $1570 \pm 12 \mathrm{~kg} / \mathrm{m}^{3}$ (from ten tests). The bed of chalks in the container was compressed as the punch moved downwards at a speed in the range $5-10 \mathrm{~mm} / \mathrm{s}$. During compression, the load applied to the punch was recorded as a function of the displacement of the punch. After compression, the chalks, which underwent significant breakage, were carefully taken out of the container. The length distribution of the resulting chalk fragments was analyzed using the free image analysis software ImageJ.

The parameters used in the DEM simulations are provided in Table 1 . The measured values of chalk material properties were used as the input parameters for the base case simulations. The particle-cylindrical wall friction coefficient, particle-flat wall friction coefficient, and particle bond damping coefficient were not measured experimentally. However, the friction between a chalk stick and a piece of plate, which has similar surface roughness to the walls in the compression tests, was estimated to be in the range 0.4-0.6. Thus, the sensitivity to the particle-wall friction coefficient has been examined in a wider range 0.1-0.6 in the simulations. A chalk stick was represented using eight identical spheres with $10 \mathrm{~mm}$ diameter that were bonded in a straight line, leading to a stick $80 \mathrm{~mm}$ long. As shown in Figure 3, 300 modeled chalk sticks settled in a cylindrical container of diameter $200 \mathrm{~mm}$ before compression. A constant speed of $v_{\mathrm{p}}=6.18 \mathrm{~mm} / \mathrm{s}$ was assigned to the punch, corresponding to the average value of the punch speed measured in the experiment. The sticks were compressed by the punch in the container. After compression, a large number of sticks were broken. In Figure $3 b$, the fragments after breakage were colored differently according to their aspect ratios $(A R)$.

The results of base simulations were subsequently compared with the experimental results. The load applied to the top of the bulk material is plotted as a function of the displacement of the punch or upper wall in Figure 4. In the experiment, the load increased to $1023 \mathrm{~N}$ (230 lbf) at which point the punch moved upwards and the load was rapidly removed. In the simulation, only the loading process was simulated. It can be seen that the loading curve obtained from the simulation is generally in good agreement with that from the experiment. A comparison of the fragment length distributions between the simulation and experiment under the compression load of $1023 \mathrm{~N}$ is shown in Figure 5. The compression tests were repeated three times with different initial particle spatial configurations for both experimental and simulation studies. Ignoring the unbroken sticks with a ratio of fragment length to initial particle length equal to one, a normal distribution is observed with the peak value occurring at a length ratio equal to 0.5. This observation indicates that the high aspect ratio particles are more likely to break in the 
314 center, which was also found in previous work by Hua et al. (2015) and Grof et al. (2007). Also, 315 similar distribution profiles are observed for the simulation and experiment.

316 The effects of particle-cylindrical wall friction and particle-flat wall friction on the fragment 317 length distribution are shown in Figure 6. In general, the particle-wall friction coefficients have 318 a limited impact on the particle breakage in the ranges considered. It is observed that the 319 fraction of middle size fragments increases slightly with an increase in the friction coefficient 320 between the particles and the flat punch surface and container base wall, $\mu_{p w}$. As shown in

321 Figure 7, the particle bond damping has a negligible influence on the particle breakage in the 322 process considered. A high aspect ratio particle, which is represented as a string of bonded 323 spheres, has a bumpy surface (see Figure 1). This bumpy surface structure increases the chance 324 for particle interlocking, making it more difficult for particles to slide past each other. It appears 325 that the effect of a bumpy particle surface on compression and particle breakage is minimal, as 326 demonstrated by the good agreement between the simulation and experimental results 327 observed in Figures 4-7.

\section{Breakage in an Agitated Bed}

Particle breakage due to blade agitation has been frequently encountered in bulk solids handling processes, such as agitated filter drying of active pharmaceutical ingredients (API) (am Ende et al., 2013). Lamberto et al. (2011) developed a laboratory agitation cell to study the breakage of API particles subject to mechanical agitation. In the cylindrical cell, a bed of granular material is stirred by a rotating impeller comprised of several blades and a shaft. A weight is applied to compress the material from the top in order to account for the effect of the larger bed depth in the real operation. Based on the difference in the mean particle size before and after agitation, the materials are classified as hard, medium, or easy to break. Using a similar experimental setup to that used by Lamberto et al. (2011), Remy et al. (2015) investigated the effects of shear stress and hydrostatic pressure on the API attrition. Subsequently, they proposed a workflow for scale-up of agitated drying of API materials.

341 Particle breakage is determined by particle flow and contacts. The kinematics and internal 342 stresses of elongated, rod-like particles in a blade-agitated mixer have been computationally 343 investigated by Hua et al. $(2013 ; 2015)$. It was found that as the particle aspect ratio increases, 344 the particle velocity and average solid volume fraction decrease and the internal stresses within 345 a particle increase. The computational simulations of granular shear flows by Guo et al. (2012; 346 2013a) show that the inter-particle contact forces and solid phase stresses increase with 347 increasing particle friction coefficient and particle aspect ratio in dense flows. 
In this study, the previously described and validated particle breakage model is employed to simulate the breakage of high aspect ratio particles in an agitation cell. High aspect ratio particle breakage in uniaxial compression tests is mainly caused by bending deformation, which is driven by the external forces from particle-particle contacts and particle-boundary wall contacts. Particle breakage in the agitated bed occurs for the same mechanism. As a result, validation of particle breakage under uniaxial compression gives confidence in predicting particle breakage in an agitated bed. However, the effects of significant particle motion and particle-blade interaction have not been taken into account in the uniaxial compression tests. In the following subsections, the present agitated bed simulation results will be compared with previous experimental and simulation work.

The simulations are designed to explore the major factors that govern particle breakage. The modeled agitation cell is illustrated in Figure 8 . The impeller in the cylindrical cell has three blades with a pitch angle of $60^{\circ}$ from the horizontal. A number of particles of a specified aspect ratio (10 in the present study) are initially generated in random positions and with random orientation inside the agitation cell. After the initial generation, the particles are allowed to settle under gravity in the cell. Next, the particle bed is compressed by applying a weight to the top wall. When a balance is achieved between the weight of the top wall and the resultant particle-wall contact force, agitation is started by rotating the impeller about the central shaft at a constant angular velocity. During agitation, the applied weight on the top remains constant. The agitation cell size, particle properties, bond properties, blade properties, and operating parameters are shown in Table 2. The Young's modulus, density and material strength of the particles and bonds are the same as those of pregelatinized starch compacts, which are pharmaceutical materials, as reported by van Veen et al. (2004).

During the agitation process, the mass of small fragments increases due to particle breakage. This mass fraction of fragments with the aspect ratio $(A R)$ less than or equal to a specified sieve cut $A R$ is plotted as a function of the impeller angular displacement, $\omega t$, for the normalized

pressures $\frac{P}{\sigma_{\text {ten }}}=1.69 \mathrm{e}-3$ and $3.38 \mathrm{e}-3$ in Figure 9, in which $P$ is the applied pressure to the top of the particle bed and $\sigma_{\text {ten }}$ is the material tensile strength. As shown in Figure 9, the fragment mass fraction initially increases with the impeller angular displacement and eventually approaches an asymptotic value for various sieve cut aspect ratios $(A R)$. The particle aspect ratio distributions at various impeller angular displacements are plotted in Figure 10 . It can be seen that most of the fragments have aspect ratios smaller than six indicating that the longer particles are easier to break than shorter ones, and they tend to break near the center.

\subsection{Agitation under Various Applied Pressures and with different cell sizes}


As shown in Figure 11a, a larger fragment mass fraction with the sieve cut aspect ratio of $A R \leq$ 5 is obtained with larger applied pressure, $\frac{P}{\sigma_{t e n}}$. Particle breakage is promoted as larger pressures are applied to compress the material since larger internal particle stresses are induced by larger external forces. The slopes of the fragment mass fraction curves decrease as the impeller angular displacement, $\omega t$, increases. The fragment mass fraction tends to approach a maximum limit as the agitation proceeds, and the limit is reached sooner with a larger applied pressure. In addition, a small agitation cell of diameter $D_{c}=122 \mathrm{~mm}$ and a large one of diameter $D_{c}=244 \mathrm{~mm}$ have been considered. With the same applied pressure, similar curves are obtained for the fragment mass fraction as a function of $\omega t$ for both small and large cells. The mean particle aspect ratio, $A R_{\mathrm{m}}$, normalized by the initial mean particle aspect ratio before agitation occurs, $A R_{\mathrm{m}}^{0}$, is plotted as a function of impeller angular displacement in Figure 11b. The mean particle aspect ratio decreases as the impeller angular displacement increases. Smaller mean particle aspect ratios are observed with larger applied pressures. With the same applied pressure, similar results for particle aspect ratio reduction are obtained with the two different agitation cell sizes.

\subsection{Effect of Impeller Rotational Speed}

The effect of impeller rotational speed on the particle breakage results has also been explored. The variation of fragment mass fraction with $A R \leq 5$ and normalized mean particle aspect ratio with elapsed time, $t$, for various impeller rotational speeds is shown in Figure 12. At a given time instant, larger fragment mass fraction and smaller mean particle aspect ratio are observed with larger impeller rotational speed. The variation of fragment mass fraction and normalized mean particle aspect ratio with impeller angular displacement, $\omega t$, is plotted in Figure 13. Interestingly, subject to a given applied pressure, the variation of fragment mass fraction and normalized mean particle aspect ratio with impeller angular displacement is independent of the impeller angular speed, $\omega$, after an initial short period ( $\omega t<1$ rad or 60 degrees). Thus, the extent of particle breakage in an agitation cell is essentially determined by the impeller angular displacement rather than the impeller rotational speed. The same observation, that attrition is a function of displacement as opposed to speed, was obtained for the attrition of spherical particles in shear flows (Hare et al., 2011).

Considering that the particle breakage is significantly affected by normalized applied pressure, $P / \sigma_{\text {ten }}$, and impeller angular displacement, $\omega t$, the fragment mass fraction and normalized mean particle aspect ratio are plotted as a function of $\omega t\left(P / \sigma_{\text {ten }}\right)$ in Figure 14 . The resulting curves tend to collapse for both the small and large cells, various impeller angular speeds, and various applied pressures. 
Figure 15 a shows the torque acting on the impeller, $T$, as a function of impeller angular displacement, $\omega t$. For a given applied pressure, the torque rapidly increases then fluctuates around a constant value as the impeller rotates. It can be seen that the torque increases as the applied pressure increases. A linear relationship between the mean torque, $T_{\text {mean }}$, and the applied pressure, $P / \sigma_{\text {ten }}$, is observed in Figure $15 \mathrm{~b}$. Therefore, for a given agitation cell, the mean torque acting on the impeller, $T_{\text {mean }}$, is proportional to the applied pressure, $P / \sigma_{\text {ten }}$. This dependence of the torque on the pressure was also observed in the API agitated drying experiments by Remy et al. (2015). Therefore, we have

$$
W=\omega t T_{\text {mean }} \propto \omega t\left(P / \sigma_{\text {ten }}\right) .
$$

The work performed by the impeller, $W$, is proportional to the dimensionless term, $\omega t\left(P / \sigma_{\text {ten }}\right)$. The data collapse in Figure 14 indicates that the particle breakage results are governed by the work input from the impeller. This result is consistent with the previous finding by Potapov and Campbell (1997) in their 2D simulations of square particle breakage in shear flow. Also, Remy et al. (2015) obtained a similar correlation between the work done by the impeller and the degree of particle attrition in their experiments.

\subsection{Effect of Inter-Particle Friction}

The inter-particle friction coefficient determines how easily a particle slides past its neighbors, and also has a significant influence on the contact forces between particles. The effect of interparticle friction on particle breakage in an agitation cell is shown in Figure 16, in which the fragment mass fraction (sieve cut $A R \leq 5$ ) and normalized mean particle aspect ratio are plotted as a function of the dimensionless term, $\omega t\left(\frac{P}{\sigma_{t e n}}\right)$. It can be seen that larger fragment mass fractions and smaller mean particle aspect ratios are obtained with larger inter-particle frictions, $\mu_{\mathrm{pp}}$. This result is due to the fact that larger inter-particle friction coefficients lead to larger contact forces, which promotes particle breakage.

In an effort to collapse the curves for different inter-particle frictions in Figure 16, the following correlations are assumed:

$$
\text { Fragment Mass Fraction }=\text { function } 1\left(K_{1}\left(\mu_{p p}\right)\left[\omega t\left(P / \sigma_{t e n}\right)\right]^{f_{1}\left(\mu_{p p}\right)}\right) \text {, }
$$

and,

$$
A R_{m} / A R_{m}^{0}=\text { function2 }\left(K_{1}\left(\mu_{p p}\right)\left[\omega t\left(P / \sigma_{t e n}\right)\right]^{f_{1}\left(\mu_{p p}\right)}\right),
$$


475 And,

476

and, $\mu_{p w}$.

where $K_{1}$ and $f_{1}$ are empirically determined fitting functions of $\mu_{\mathrm{pp}}$. As shown in Figure 17, the collapse of particle breakage data with various inter-particle friction coefficients is achieved in the plots of fragment mass fraction and normalized mean particle aspect ratio as a function of the dimensionless term, $K_{1}\left(\mu_{p p}\right)\left[\omega t\left(P / \sigma_{t e n}\right)\right]^{f\left(\mu_{p p}\right)}$, in which

$$
K_{1}\left(\mu_{p p}\right)=e^{8.5 \cdot\left(\mu_{p p}-0.2\right)}
$$

$$
f_{1}\left(\mu_{p p}\right)=0.75 \cdot e^{1.2 \cdot\left(\mu_{p p}-0.2\right)} .
$$

The exponential form for these functions is chosen based on the shape of the data curve. The constants in these functions are determined by a best fit to the data points using the least squares method.

\subsection{Effect of Particle-Wall Friction}

The particle-wall friction coefficient affects particle flow and interaction, and therefore also affects particle breakage. The impact of particle-wall friction coefficient, $\mu_{p w}$, on fragment mass fraction (sieve cut $A R \leq 5$ ) and normalized mean particle aspect ratio is shown in Figure 18. With a small particle-wall friction coefficient of $\mu_{p w}=0.2$, the whole particle bed rotates like a single solid body with the impeller and no particle breakage occurs after an initial transient. Thus, fragment mass fraction and mean particle aspect ratio remain constant when $\omega t\left(P / \sigma_{\text {ten }}\right)>0.001$ for $\mu_{p w}=0.2$. With larger wall-particle friction coefficients, the tangential contact forces between particles and walls are increased and it is more difficult for the particles to slide on the wall surfaces. As a result, retarded flow zones are obtained close to the base and top walls, and the material is significantly sheared in the cell by the rotating blades. The fragment mass fraction increases and mean particle aspect ratio decreases with an increase in

Similar to what was done for the particle-particle friction coefficients, to collapse the curves for different particle-wall friction coefficients in Figure 18, the following correlations are assumed,

$$
\text { Fragment Mass Fraction }=\text { function3 }\left(K_{2}\left(\mu_{p w}\right)\left[\omega t\left(P / \sigma_{\text {ten }}\right)\right]^{f_{2}\left(\mu_{p w}\right)}\right) \text {, }
$$

$$
A R_{m} / A R_{m}^{0}=\text { function4 }\left(K_{2}\left(\mu_{p w}\right)\left[\omega t\left(P / \sigma_{\text {ten }}\right)\right]^{f_{2}\left(\mu_{p w}\right)}\right) \text {. }
$$


477 As shown in Figure 19, the collapse of particle breakage data with various particle-wall friction 478 coefficients is achieved in the plots of fragment mass fraction and normalized mean particle

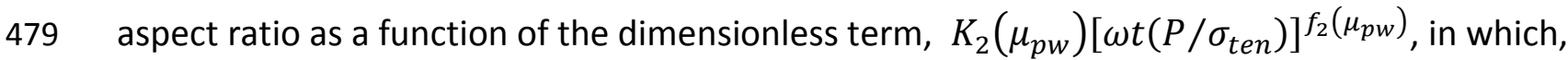

$$
K_{2}\left(\mu_{p w}\right)=e^{18.1 \cdot\left(\mu_{p w^{-}}-0.7\right)}
$$

481 and,

$$
f_{2}\left(\mu_{p w}\right)=1.28 \cdot e^{2.5 \cdot\left(\mu_{p w}-0.7\right)}
$$

483 484

485 486

492 and, form

and,

and,

where, again, the form of the functions is proposed based on the shape of data curves and the constants in the functions are determined by a least-squares best fit.

Finally, the effects of inter-particle friction and particle-wall friction may be combined in the

$$
\text { Fragment Mass Fraction }=\text { function5 }\left(K\left(\mu_{p p}, \mu_{p w}\right)\left[\omega t\left(P / \sigma_{t e n}\right)\right]^{f\left(\mu_{p p}, \mu_{p w}\right)}\right) \text {, }
$$

$$
A R_{m} / A R_{m}^{0}=\text { function6 }\left(K\left(\mu_{p p}, \mu_{p w}\right)\left[\omega t\left(P / \sigma_{t e n}\right)\right]^{f\left(\mu_{p p}, \mu_{p w}\right)}\right),
$$

in which,

$$
K\left(\mu_{p p}, \mu_{p w}\right)=K_{1}\left(\mu_{p p}\right)^{f_{2}\left(\mu_{p w}\right)} K_{2}\left(\mu_{p w}\right)^{f_{1}\left(\mu_{p p}\right)}
$$

$$
f\left(\mu_{p p}, \mu_{p w}\right)=f_{1}\left(\mu_{p p}\right) f_{2}\left(\mu_{p w}\right) .
$$

The fragment mass fraction and normalized mean particle aspect ratio are plotted as a function of $K\left(\mu_{p p}, \mu_{p w}\right)\left[\omega t\left(P / \sigma_{t e n}\right)\right]^{f\left(\mu_{p p}, \mu_{p w}\right)}$ in Figure 20 . The curves of particle breakage results with various inter-particle and particle-wall friction coefficients collapse reasonably well using the chosen fitting functions.

The total work performed on the material is partially converted to particle kinetic energy, partially dissipated through particle-particle and particle-wall frictional contacts, and partially used to break the particles. The term inside the function5() and function6() in Eqs. (27) and (28) may be treated as effective work terms that contribute to particle breakage. Thus, the extent of particle breakage is a function of the effective work term, which is strongly dependent on the exponent term, i.e. the term involving particle-particle and particle-wall friction coefficients. Larger particle-particle and/or particle-wall friction coefficients lead to larger 
exponent terms and, therefore, larger effective work terms. As a result, a larger extent of breakage is obtained. In other words, larger friction coefficients enable the input energy to break the particles more efficiently.

It should be noted that the correlations obtained from Eqs. (27)-(30) are valid for particleparticle friction coefficients between 0.2 and 0.5 and particle-wall friction coefficients between 0.2 and 1 . In addition, these correlations were developed by varying a single parameter at a time from baseline values. They may not be valid when multiple parameters are varied simultaneously. The interaction of multiple parameters, including particle-particle friction and particle-wall friction, needs to be investigated in the future.

\section{Concluding remarks}

In this work, a particle breakage model based on the Discrete Element Method (DEM) is employed to numerically model high aspect ratio particle breakage. A particle in the DEM is represented by a string of spheres connected in a straight line using elastic bonds. Particle breakage is modeled by eliminating a bond if the tensile or shear stresses exceed the material strengths. Validation of the particle breakage model is performed against experimental tests of the breakage of blackboard chalk sticks subject to uniaxial compression. Good agreement is achieved between simulation and experimental results of the applied load and particle size distribution profile.

The validated model is thereafter applied to investigate particle breakage due to agitation by rotating blades. Using the numerical model, the evolutions of fragment mass fraction and average particle size are explored. The DEM simulation results show that particle breakage rate depends on the applied pressure, blade rotational speed, inter-particle friction, and wallparticle friction. As a larger weight is applied to compress the bulk solid bed, the particleparticle and particle-wall contact forces increase, leading to an increase in breakage rate. The breakage rate increases as the rotational speed of blades increases due to increased frequency of particle-blade interaction. However, the extent of breakage per blade revolution is independent of rotational speed. With a small particle-wall friction coefficient, the particle bed rotates like a solid body along with the agitation blades and particle breakage is minimal. With large particle-wall friction coefficients, however, retarded flow zones are obtained close to the base and top walls, and more particles are broken due to the large shear forces as the blades rotate. One of the most important findings from this work is that the fragment mass fraction and the average particle size can be expressed as functions of the input work performed by the blades, particle-particle friction, and particle-wall friction. The input work performed by the 
blades is linearly proportional to the blade rotational speed, agitation time, and the applied pressure.

541 Some recommendations are made based on the present work for controlling particle breakage 542 in industry. Particle breakage, at least in agitated filter dryers, generally needs to be avoided 543 during pharmaceutical processing. Reducing pressure (by reducing the bed depth for example), 544 particle-particle friction, and/or particle-wall friction can decrease the forces acting on particles 545 and therefore reduce particle breakage. Using a smaller number of blade revolutions during 546 drying and blending processes leads to less work done on the particles and can also reduce 547 particle breakage. In contrast, efficient breakage or milling of large solids is desirable in the 548 mineral processing. Increasing the applied stresses can increase particle breakage. Increasing 549 the particle-equipment surface friction can promote shear flow of the material, rather than 550 rigid-body-like flow, which also leads to an increase in contact forces and particle breakage.

551

\section{Appendix A. Supporting information}

553 The experimental setup and procedure for performing the three-point bending tests are 554 included as supplementary material for the measurement of Young's modulus and tensile yield 555 strength of blackboard chalk sticks.

\section{Acknowledgements}

This research is financially supported by the National Science Foundation (NSF) under Grant NO. 0749481/0749461 and by CPaSS industry members. The authors would like to acknowledge Dr. Kerry Johanson for setting up the uniaxial compression tests of the blackboard chalks in his company, Material Flow Solutions Inc (Gainesville, Florida, US), and acknowledge Mr. Joseph A. Oliva, who was an undergraduate student at the University of Florida, for conducting the compression experiments. The authors also acknowledge the University of Florida HighPerformance Computing Center for providing computational resources.

\section{References:}

am Ende, D., Birch, M., Brenek, S.J., Maloney, M.T., 2013. Development and application of laboratory tools to predict particle properties upon scale-up in agitated filter-dryers. Organic Process Research \& Development 17, 1345-1358. breakage simulation. Granular Matter 13: 765-776. 
Bruchmüller J, van Wachem BGM, Gu S, Luo KH, 2011. Modelling discrete fragmentation of brittle particles. Powder Technology 208: 731-739.

Delaney, G.W., Cleary, P.W., Sinnott, M.D., Morrison, R.D., 2010. Novel application of DEM to modelling comminution processes. IOP Conf. Series: Materials Science and Engineering 10, 012099.

Ghadiri, M., Ning, Z., Kenter, S.J., Puik, E., 2000. Attrition of granular solids in a shear cell. Chemical Engineering Science 55, 5445-5456.

Grof, Z., Kohout, M., Štěpánek, F., 2007. Multi-scale simulation of needle-shaped particle breakage under uniaxial compaction. Chemical Engineering Science 62, 1418-1429.

Grof, Z., Schoellhammer, C.M., Rajniak, P., Štěpánek, F., 2011. Computational and experimental investigation of needle-shaped crystal breakage. International Journal of Pharmaceutics 407, 12-20.

Guo, Y., 2010. A couple DEM/CFD analysis of die filling process. PhD thesis. University of Birmingham, Birmingham, UK.

Guo, Y., Wassgren, C., Ketterhagen, W., Hancock, B., James, B., Curtis, J., 2012. A numerical study of granular shear flows of rod-like particles using the discrete element method. J. Fluid Mech. 713:1-26.

Guo, Y., Wassgren, C., Hancock, B., Ketterhagen, W., Curtis, J., 2013a. Granular shear flows of flat disks and elongated rods without and with friction. Phys. Fluids 25:063304.

Guo, Y., Wassgren, C., Hancock, B., Ketterhagen, W., Curtis, J., 2013b. Validation and time step determination of discrete element modeling of flexible fibers. Powder Technol. 249:38695.

Guo Y, Wassgren C, Hancock, B, Ketterhagen W, Curtis, J, 2015. Computational study of granular shear flows of dry flexible fibres using the discrete element method. Journal of Fluid Mechanics 775, 24-52.

Hare C, Ghadiri M, Dennehy R, 2011. Prediction of attrition in agitated particle beds. Chemical Engineering Science 66: 4757-4770.

Hosseininia ES, Mirghasemi AA, 2006. Numerical simulation of breakage of two-dimensional polygon-shaped particles using discrete element method. Powder Technology 166: 100-112.

Hua, X., Curtis, J., Hancock, B., Ketterhagen, W., Wassgren, C., 2013. The kinematics of noncohesive, sphero-cylindrical particles in a low-speed, vertical axis mixer. Chemical Engineering Science 101, 144-164.

Hua, X., Curtis, J. Guo, Y., Hancock, B., Ketterhagen, W., Wassgren, C., 2015. The internal loads, moments, and stresses in rod-like particles in a low-speed, vertical axis mixer, Chemical Engineering Science 134, 581-598.

Johnson, K.L., 1985. Contact Mechanics. Cambridge: Cambridge University Press, United Kingdom.

Kalman H, Rodnianski V, Haim M, 2009. A new method to implement comminution functions into DEM simulation of a size reduction system. Granular Matter 11(4): 253-266.

Lamberto DJ, Cohen B, Marencic J, Miranda C, Petrova R, Sierra L, 2011. Laboratory methods for assessing API sensitivity to mechanical stress during agitated drying. Chemical Engineering Science 66, 3868-3875.

Ma, G., Zhou, W., Chang, X.-L., 2014. Modeling the particle breakage of rockfill materials with the cohesive crack model. Computers and Geotechnics 61, 132-143. 
Munjiza, A., 2004. The combined finite-discrete element method. New York: Wiley.

Neil, A.U., Bridgwater, J., 1994. Attrition of particulate solids under shear. Powder Technology 80, 207-219.

Potapov, A.V., Campbell, C.S., 1997. Computer simulation of shear-induced particle attrition. Powder Technology 94, 109-122.

Potyondy, D.O., Cundall, P.A., 2004. A bonded-particle model for rock. Int. J. Rock Mech. Min. Sci. 41, 1329-1364.

Remy, B., Kightlinger, W., Saurer, E.M., Domagalski, N., Glasser, B.J., 2015. Scale-up of agitated drying: effect of shear stress and hydrostatic pressure on active pharmaceutical ingredient powder properties. AIChE Journal 61 (2), 407-418.

Rhodes, M.J., 1998. Introduction to Particle Technology. John Wiley \& Sons Ltd, West Sussex P019 1UD, England.

Sato, K., Nagai, H., Hasegawa, K., Tomori, K., Kramer, H.J.M., Jansens, P.J., 2008. Twodimensional population balance model with breakage of high aspect ratio crystals for batch crystallization. Chemical Engineering Science 63, 3271-3278.

Thornton, C., Yin, K.K., 1991. Impact of elastic spheres with and without adhesion. Powder Technology 65, 153-165.

Van Veen, B., ven der Voort Maarschalk, K., Bolhuis, G.K., Frijlink, H.W., 2004. Predicting mechanical properties of compacts containing two components. Powder Technology 139, 156-164.

Weerasekara NS, Powell MS, Cleary PW, Tavares LM, Evertsson M, Morrison RD, Quist J, Carvalho RM, 2013. The contribution of DEM to the science of comminution. Powder Technology 248, 3-24. 


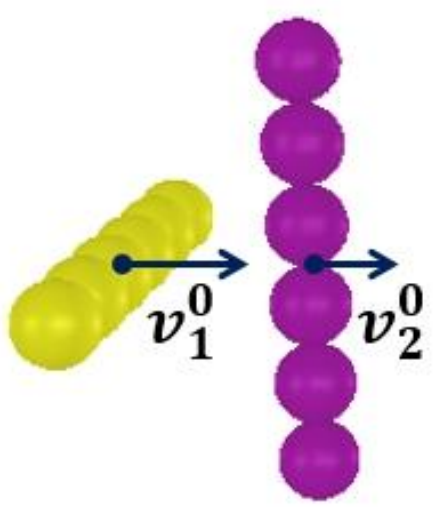

(a) Before collision

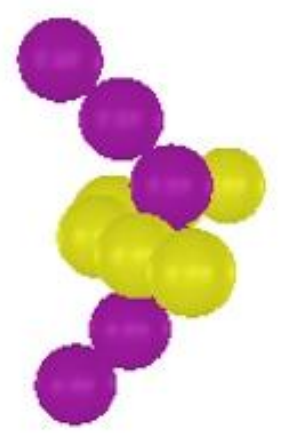

(b) During collision

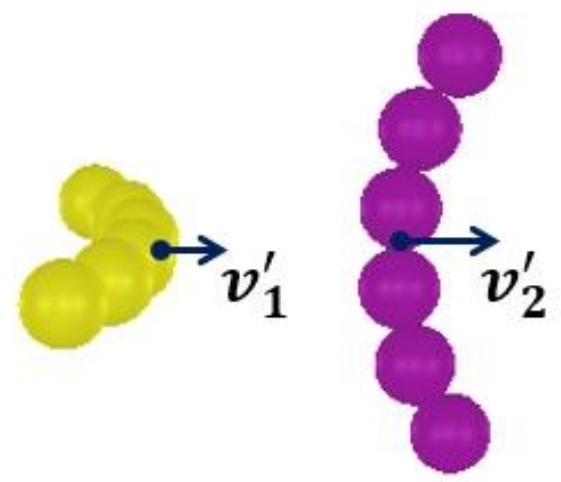

(c) After collision

Figure 1. DEM simulation of collision of two flexible fibers with their major axes perpendicular to each other using the bonded particle model (Guo et al., 2015). 

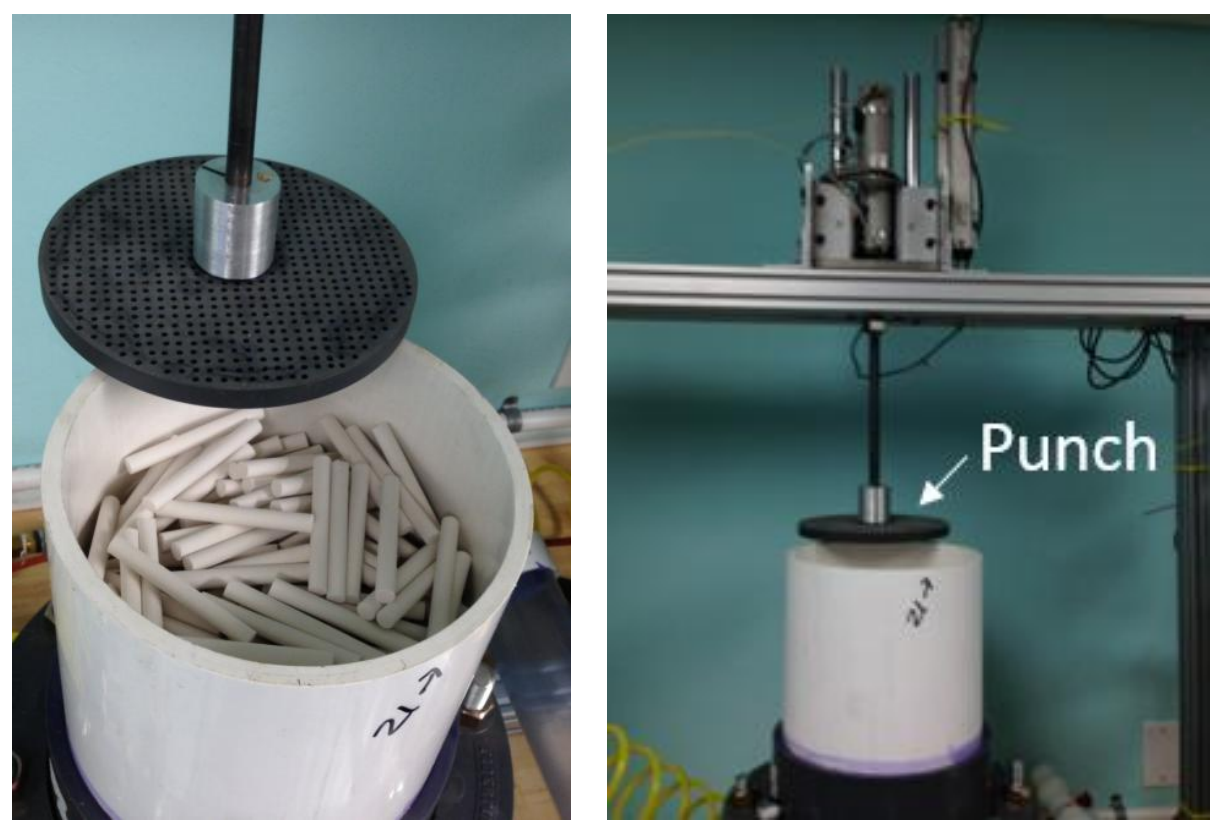

Figure 2. Experimental set-up of uniaxial compression of blackboard chalk sticks in a cylindrical container. 


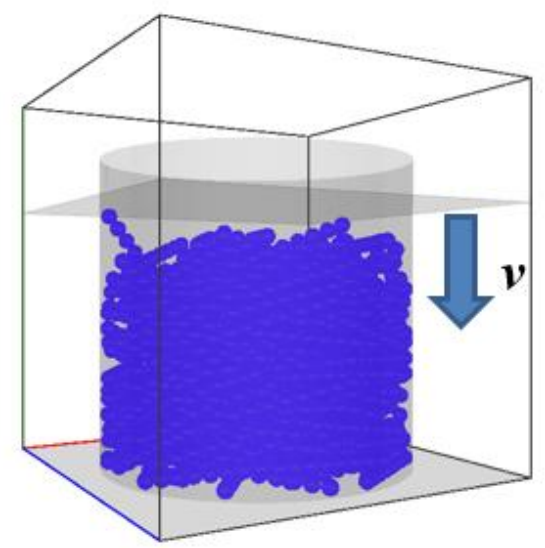

(a) Before compression

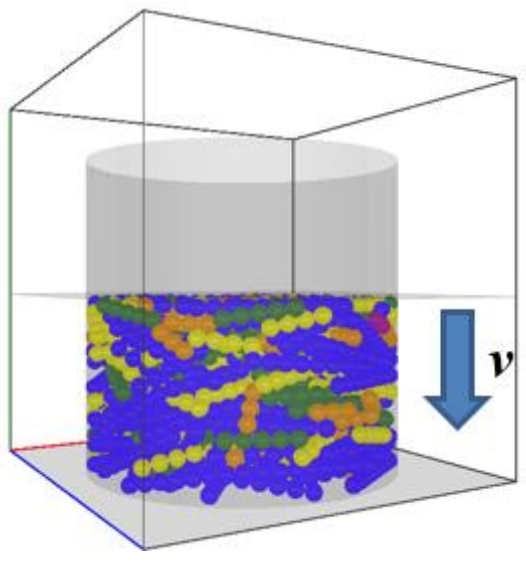

(b) After compression
AR

$6,7,8$

5

4

3

2

1

Figure 3. DEM simulation of the uniaxial compression of chalk sticks. The chalk sticks with aspect ratios (AR) greater or equal to six are colored in blue and the shorter ones are differently colored based on their aspect ratios. 


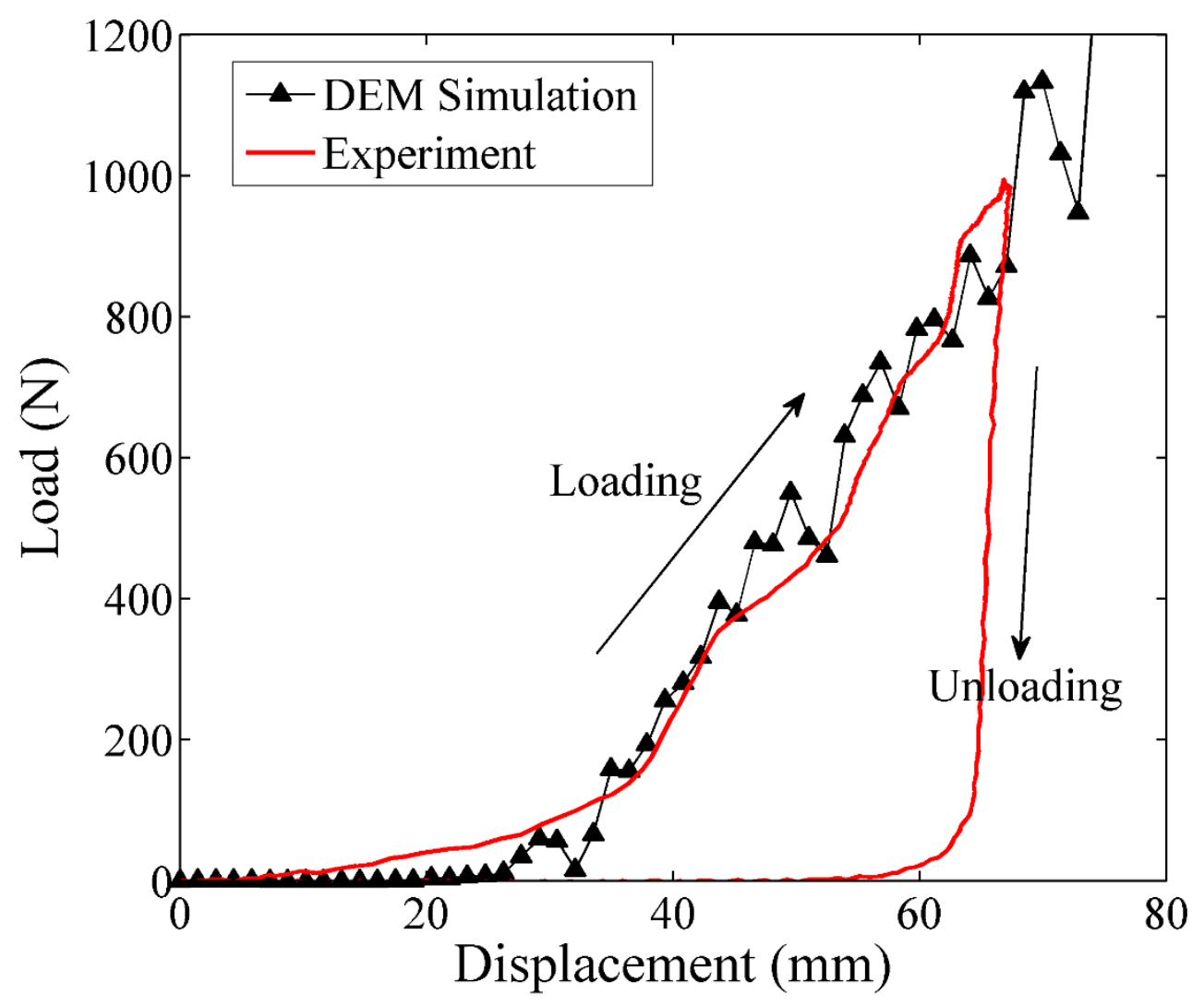

Figure 4. Load applied to the punch or the top of the bulk material as a function of displacement of the punch or upper wall. The base case parameters in Table 1 are used in the DEM simulation presented in this figure. 


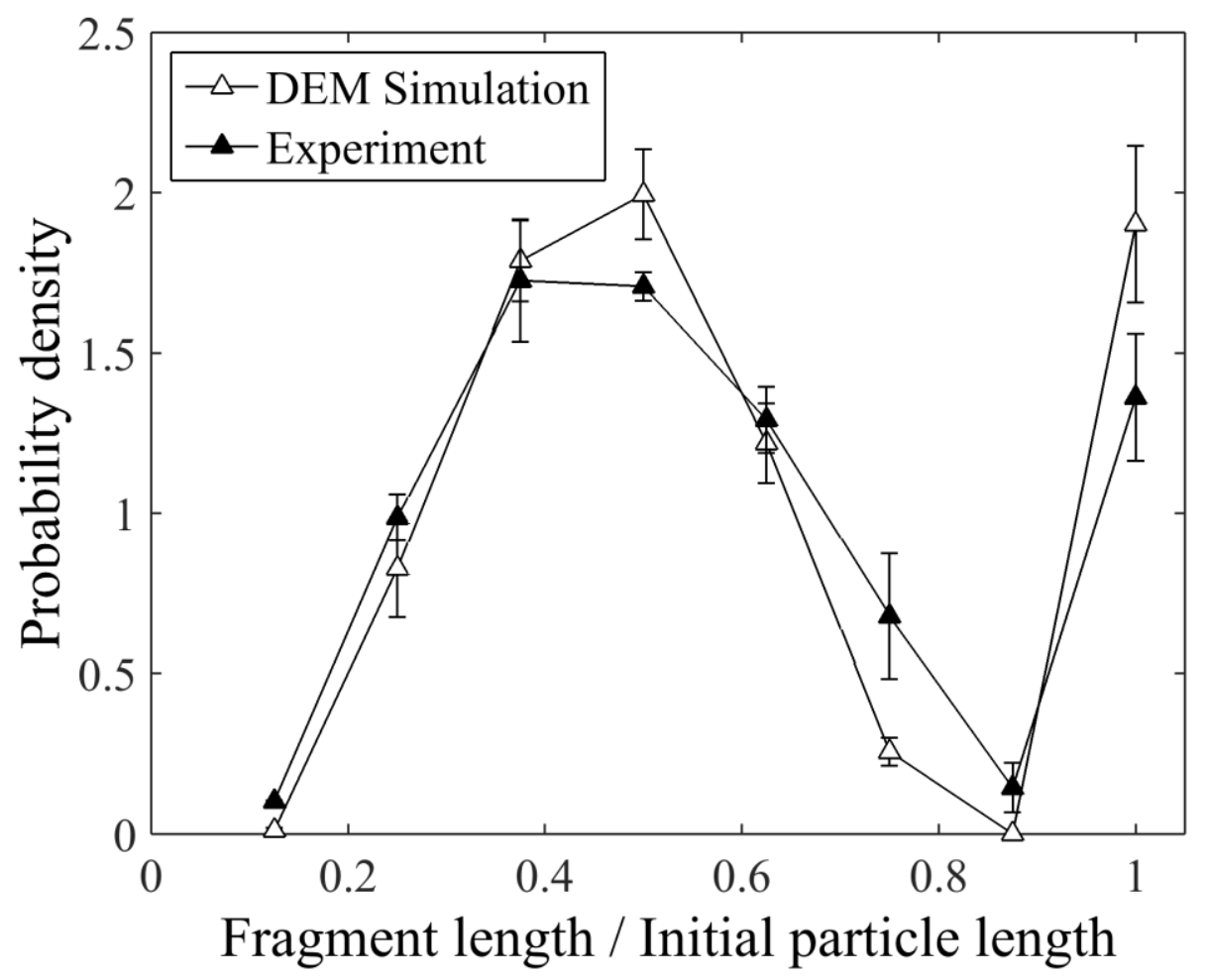

Figure 5. Fragment length distribution under the compression load of $1023 \mathrm{~N}$ (230 lbf). The integral of probability density across an interval of fragment length gives the number fraction of the fragments within the same interval. The error bars represent the standard deviation of three separate tests with different initial configurations of particle bed in the container. 


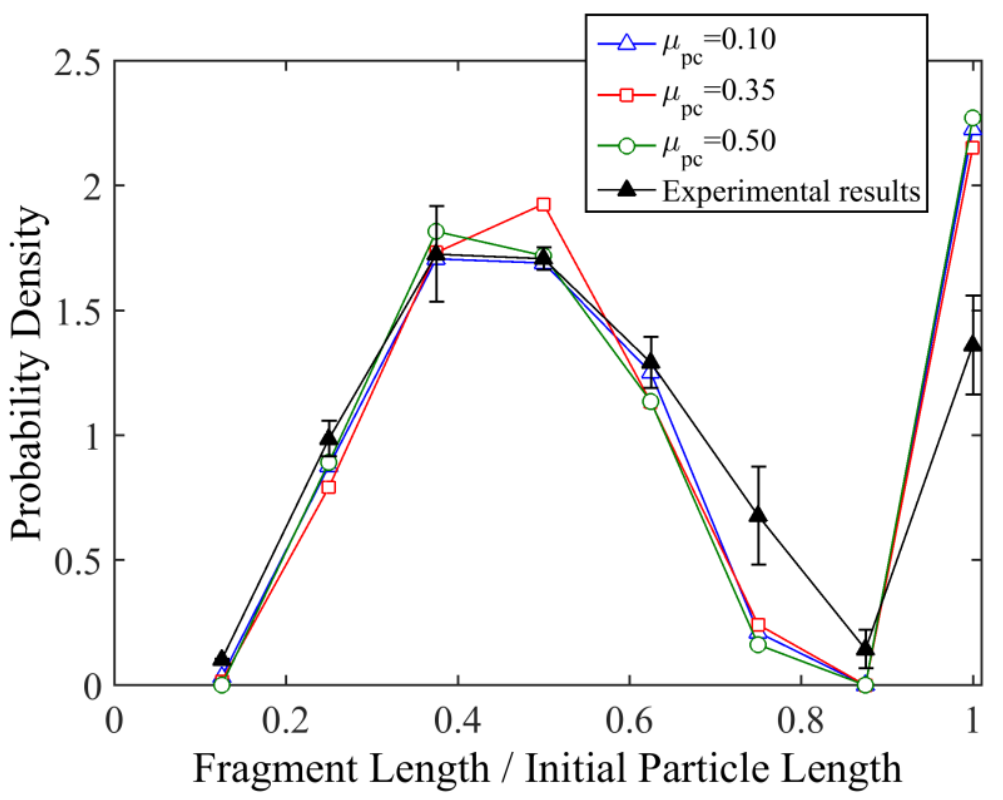

(a)

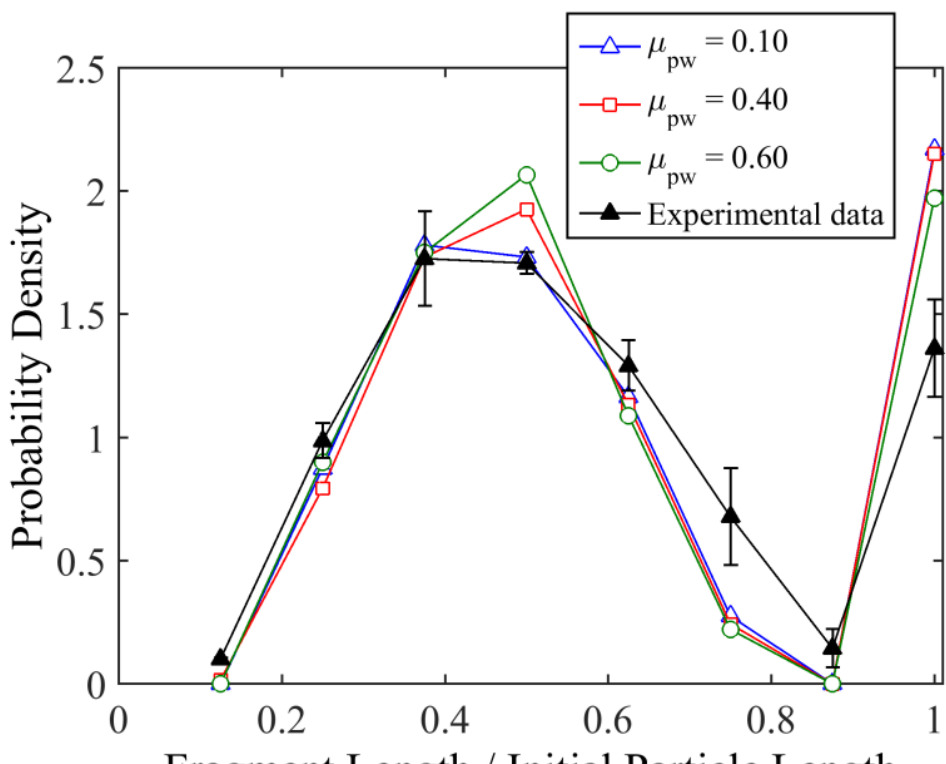

(b)

Figure 6 Effects of (a) particle-cylindrical wall friction, $\mu_{p c}$, and (b) particle-flat wall friction, $\mu_{p w}$ on the fragment length distribution after compression. 


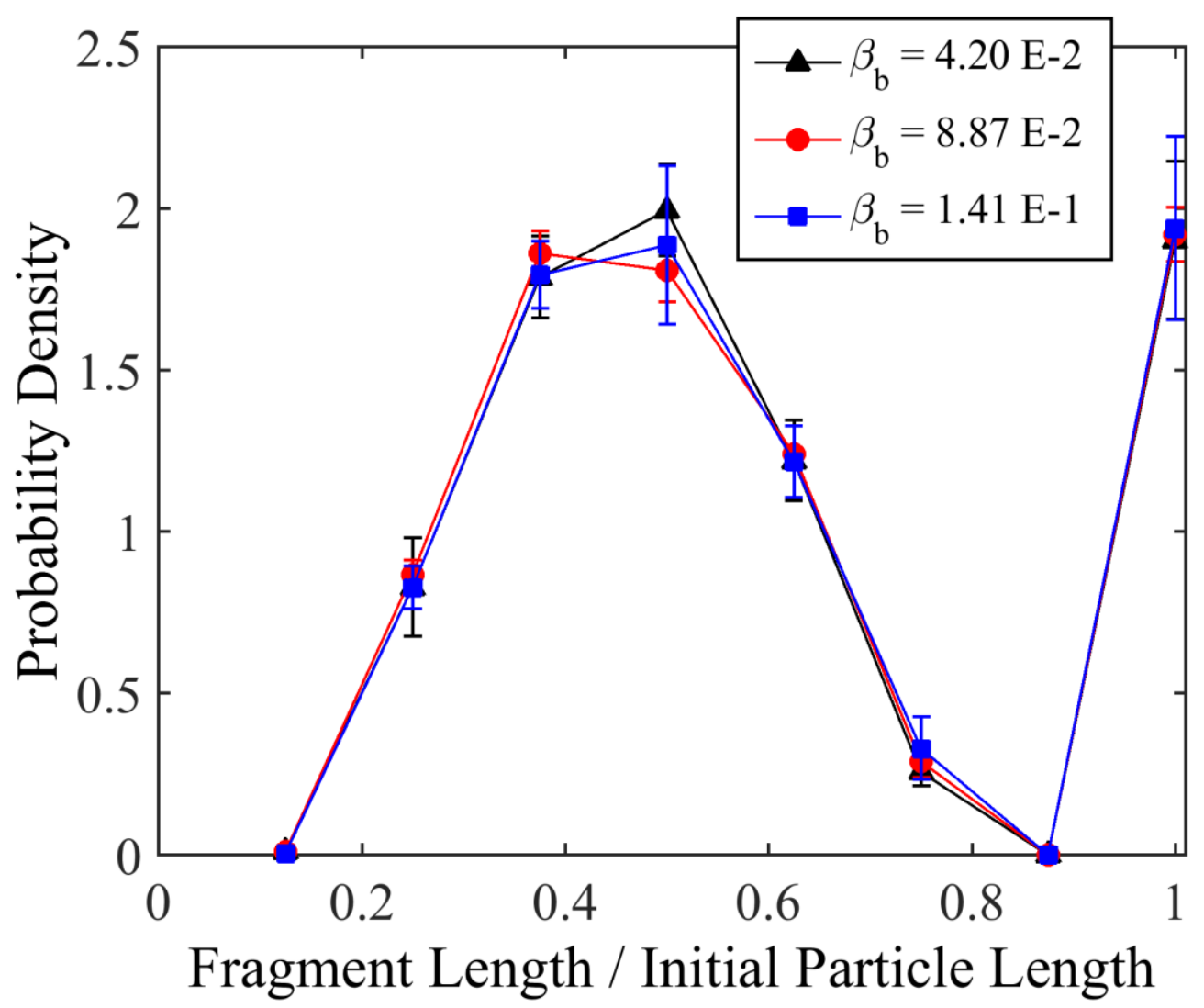

Figure 7 Effect of particle bond damping coefficient, $\beta_{b}$, on the fragment length distribution after compression. The error bars represent the standard deviation of three separate tests with different initial configurations of the particle bed in the container. 

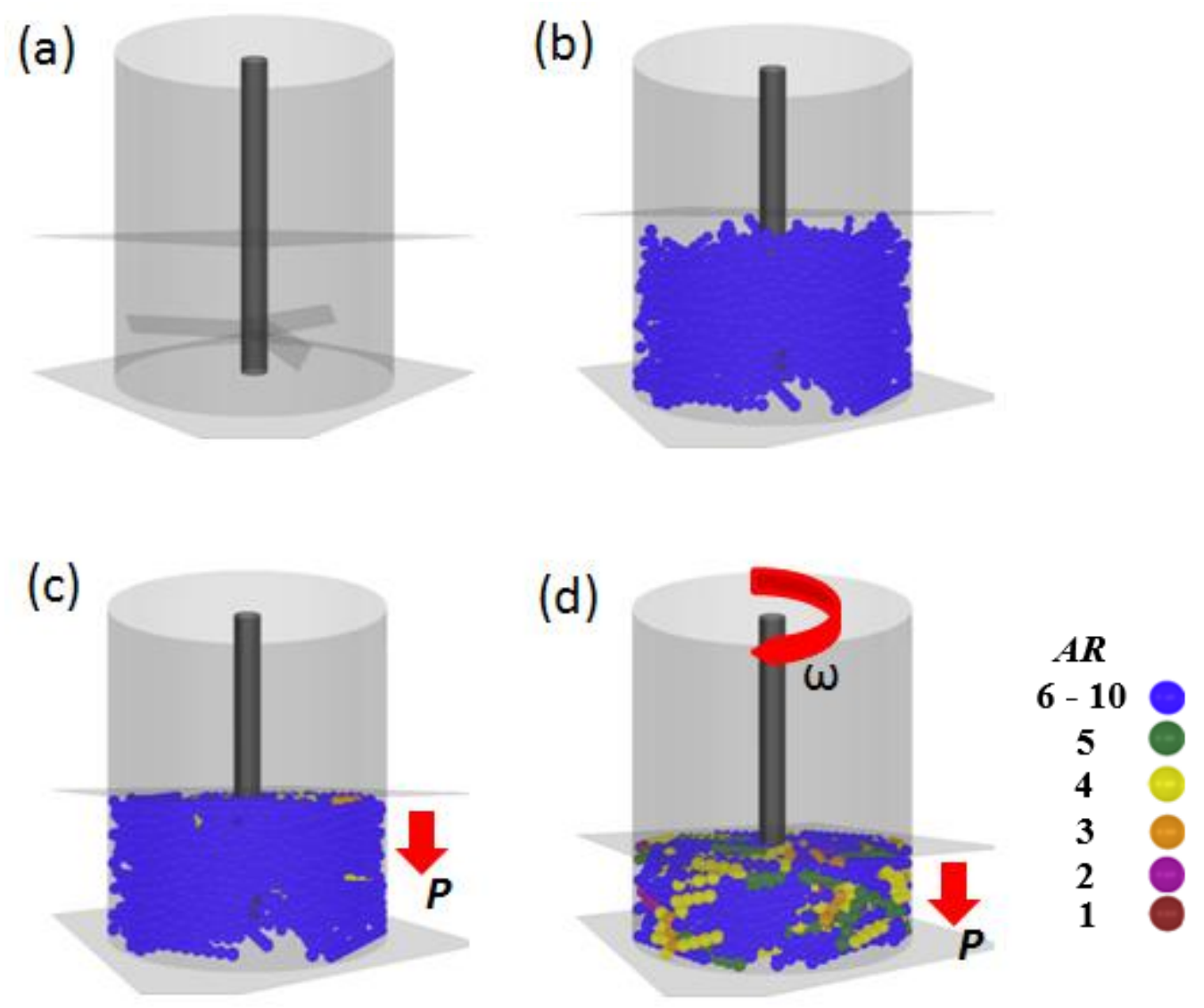

Figure 8 Simulation of elongated particle breakage in an agitation cell: (a) cylindrical agitation cell with three rotating blades, (b) a number of elongated particles generated and deposited in the cell, (c) the particle bed is compressed by specifying a weight for the top wall, and (d) agitation occurs by rotating the blades about the central shaft at a constant angular velocity. 


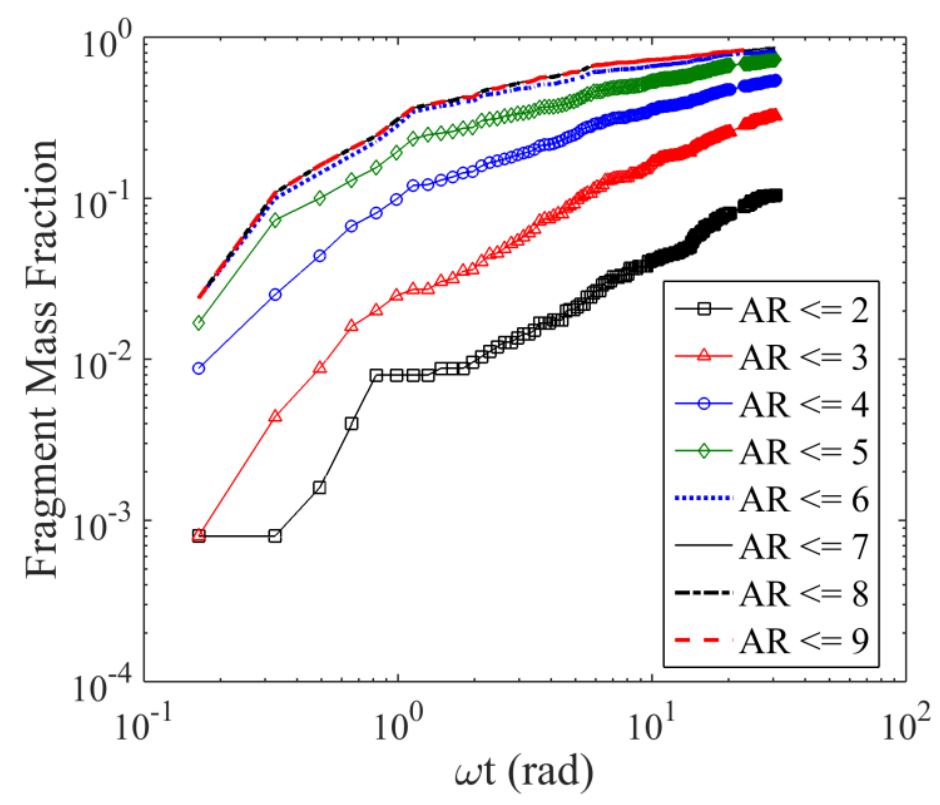

(a) $\frac{P}{\sigma_{t e n}}=1.69 \mathrm{e}-3$

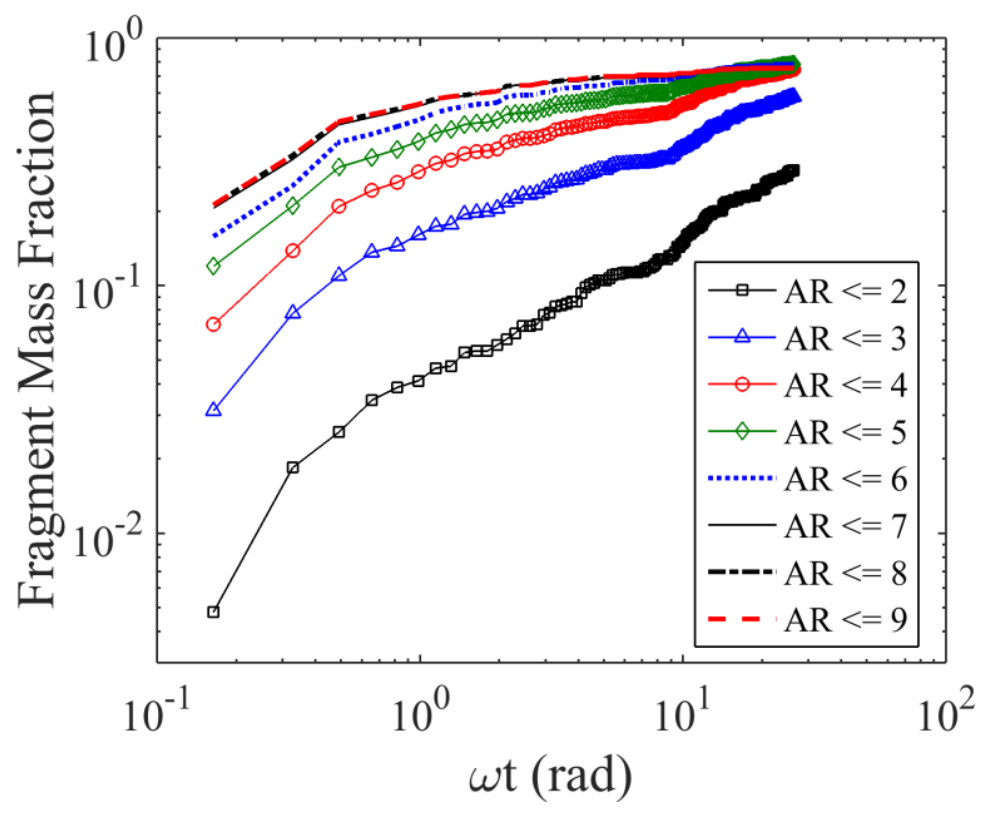

(b) $\frac{P}{\sigma_{\text {ten }}}=3.38 \mathrm{e}-3$

Figure 9 The evolution (in terms of impeller angular displacement $\omega t$ ) of fragment mass fraction with various sieve cut particle aspect ratios (AR) under the normalized pressure $\frac{P}{\sigma_{\text {ten }}}=$ $1.69 \mathrm{e}-3$ (a) and $\frac{P}{\sigma_{\text {ten }}}=3.38 \mathrm{e}-3$ (b). (small cell, $\mu_{p p}=0.2, \mu_{p w}=0.7, \omega=60 \mathrm{rpm}$ ) 


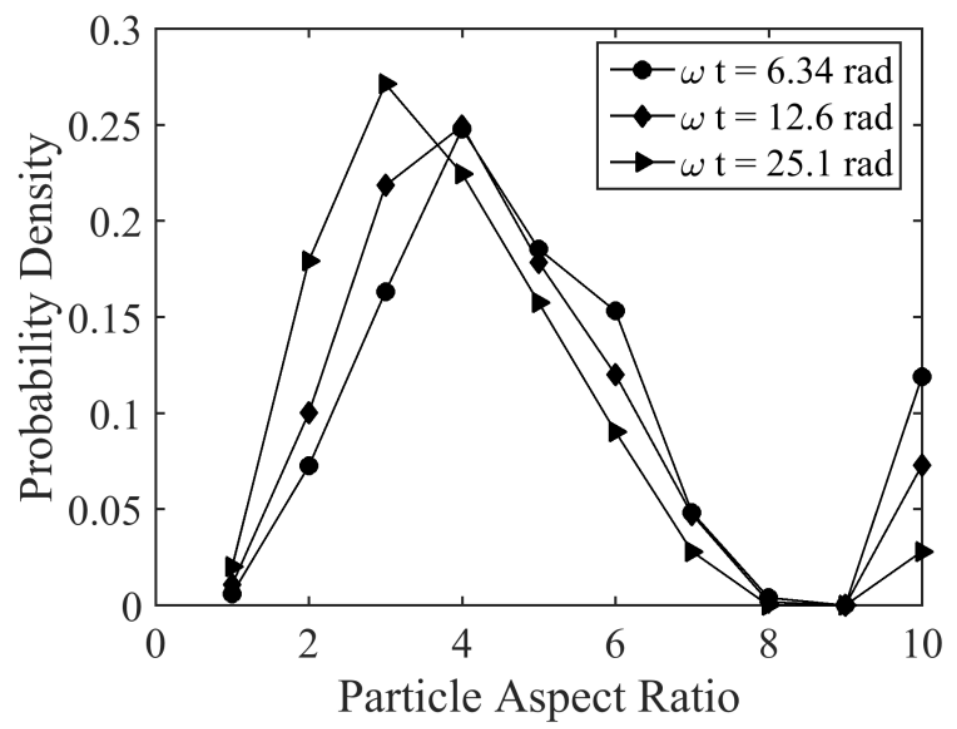

(a) $\frac{P}{\sigma_{\text {ten }}}=1.69 \mathrm{e}-3$

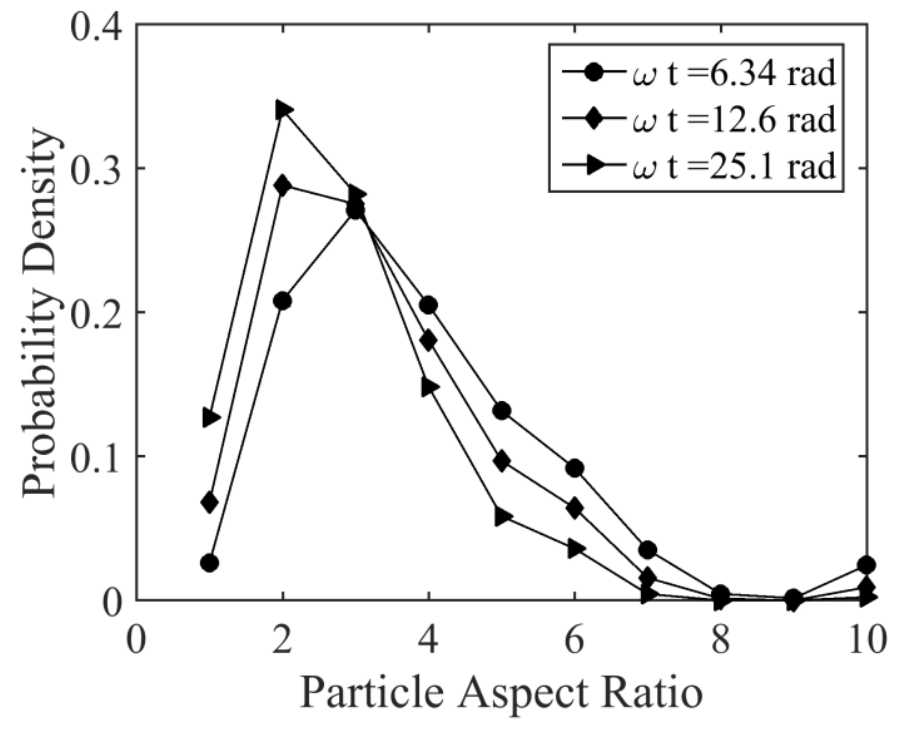

(b) $\frac{P}{\sigma_{\text {ten }}}=3.38 \mathrm{e}-3$

Figure 10 Particle aspect ratio distributions under the normalized pressure $\frac{P}{\sigma_{\text {ten }}}=1.69 \mathrm{e}-3(\mathrm{a})$ and $\frac{P}{\sigma_{t e n}}=3.38 \mathrm{e}-3$ (b). (small cell, $\mu_{p p}=0.2, \mu_{p w}=0.7, \omega=60 \mathrm{rpm}$ ) 


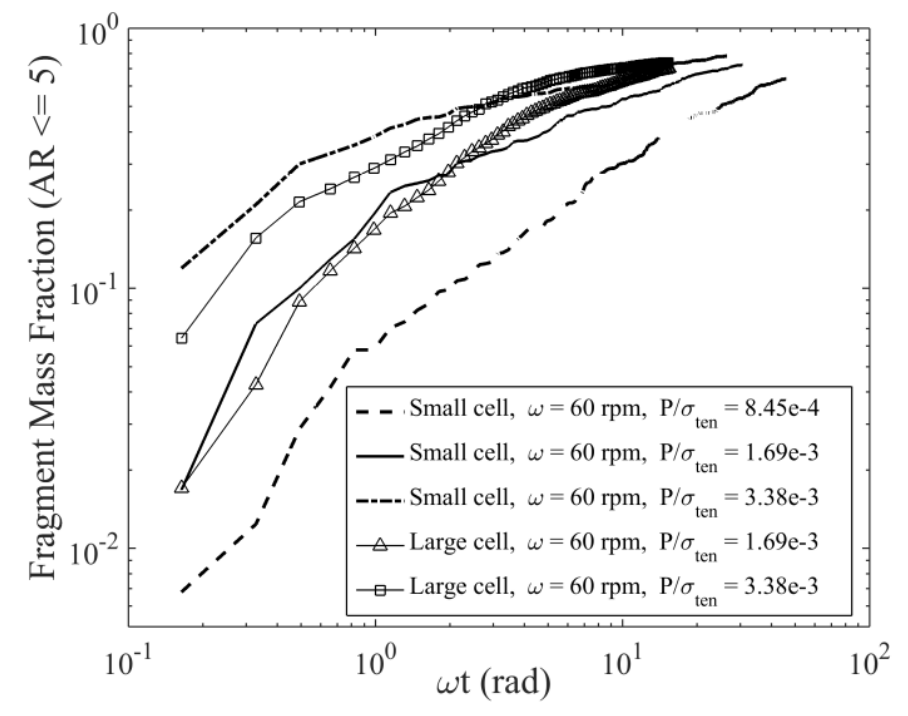

(a)

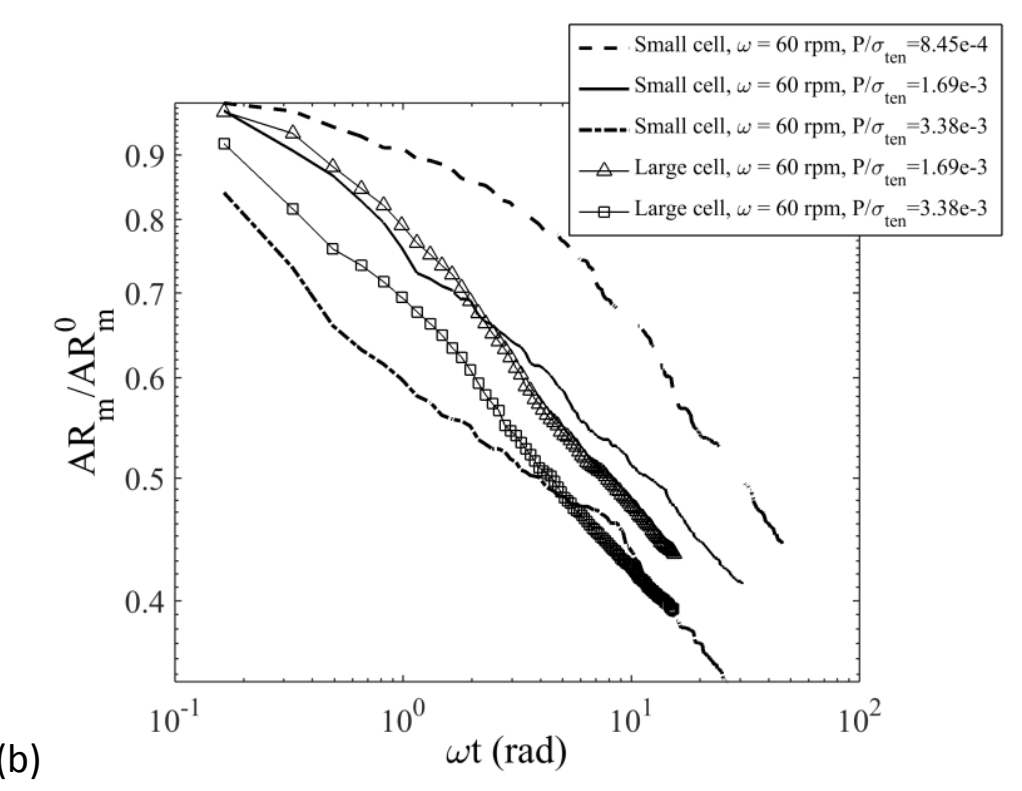

Figure 11 The evolution (in terms of impeller angular displacement $\omega t$ ) of (a) fragment mass fraction (sieve cut $A R<=5$ ) and (b) normalized mean particle aspect ratio with the small and large cells under various applied pressures. ( $\mu_{p p}=0.2, \mu_{p w}=0.7, \omega=60 \mathrm{rpm}$ ) 


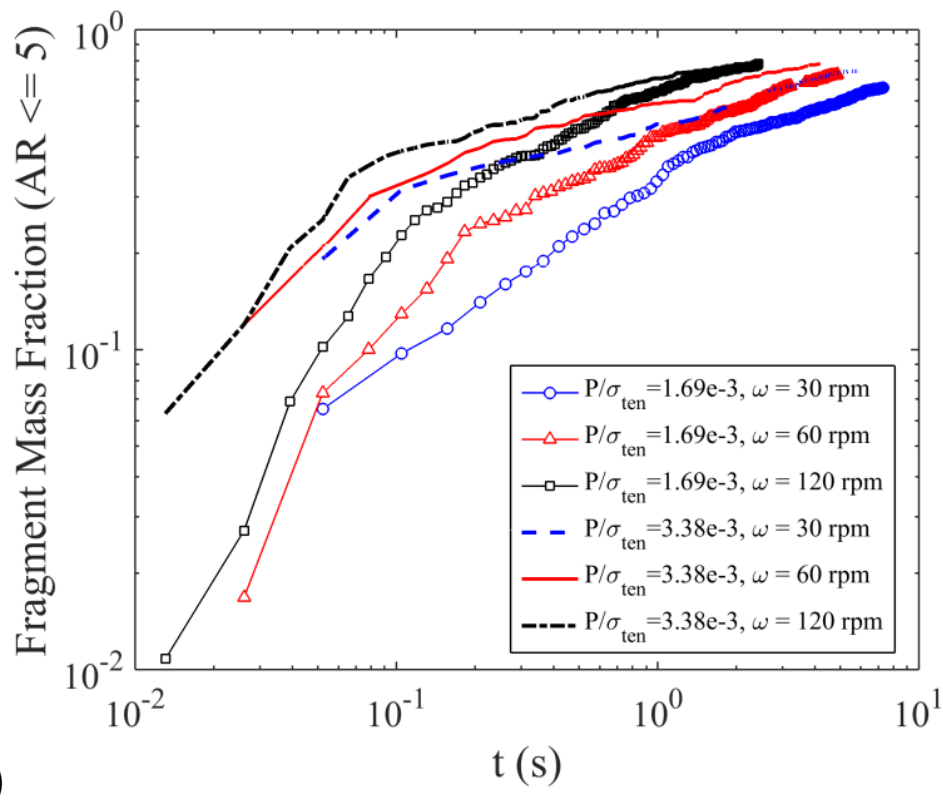

(a)

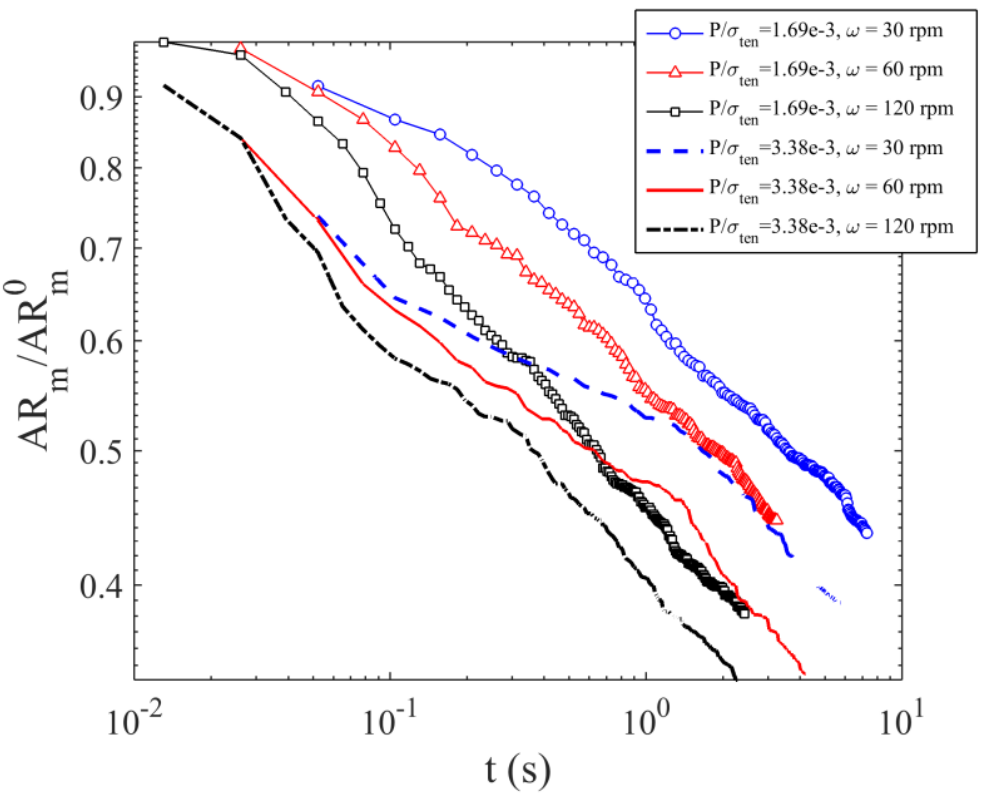

(b)

Figure 12 The variation of (a) fragment mass fraction (sieve cut $A R<=5$ ) and (b) normalized mean particle aspect ratio with elapsed time, $t$, for various impeller rotational speeds. (small cell, $\mu_{p p}=0.2, \mu_{p w}=0.7$ ) 


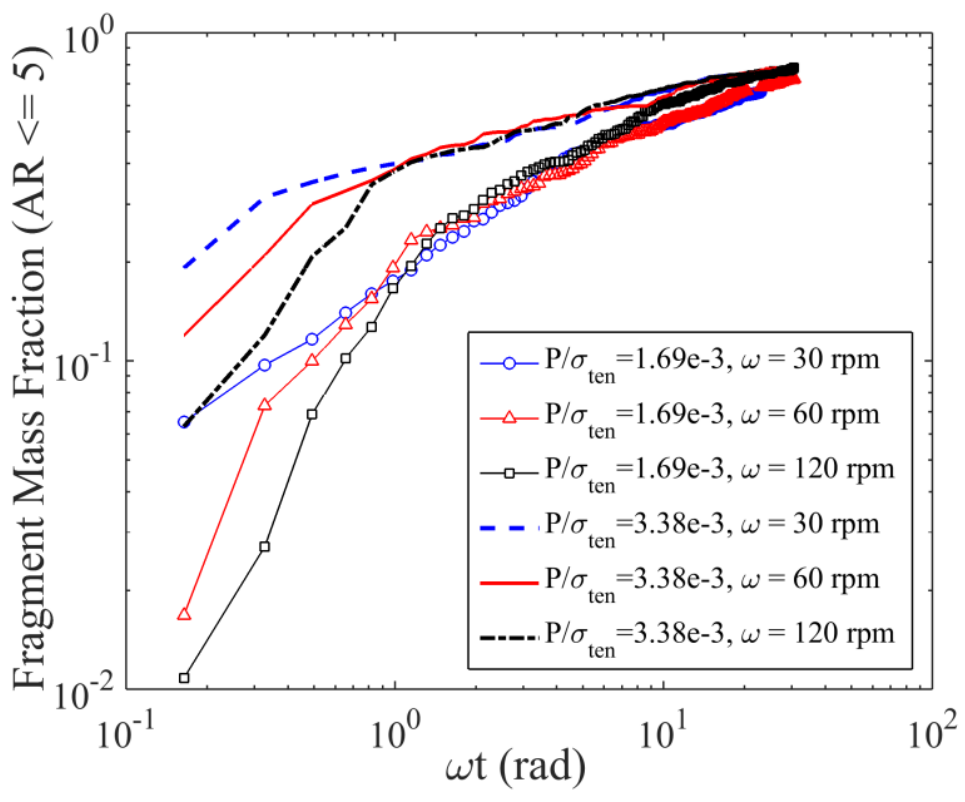

(a)

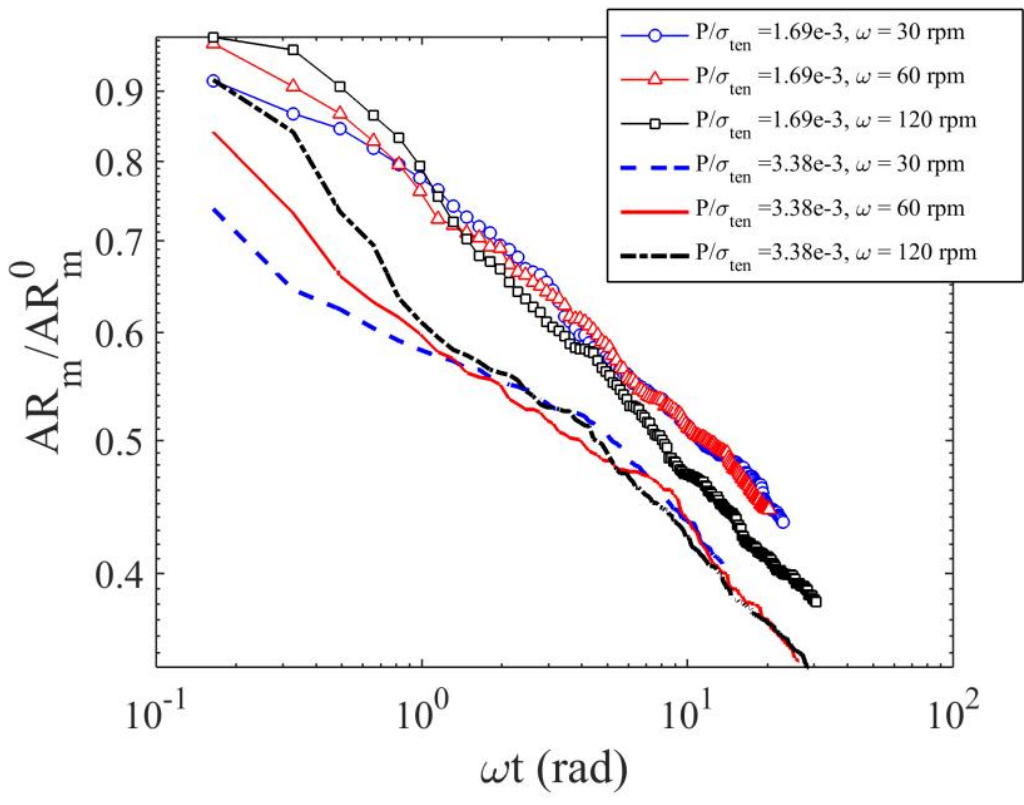

Figure 13 The variation of (a) fragment mass fraction (sieve cut $A R<=5$ ) and (b) normalized mean particle aspect ratio with the impeller angular displacement, $\omega t$, for various impeller rotational speeds. (small cell, $\mu_{p p}=0.2, \mu_{p w}=0.7$ ) 


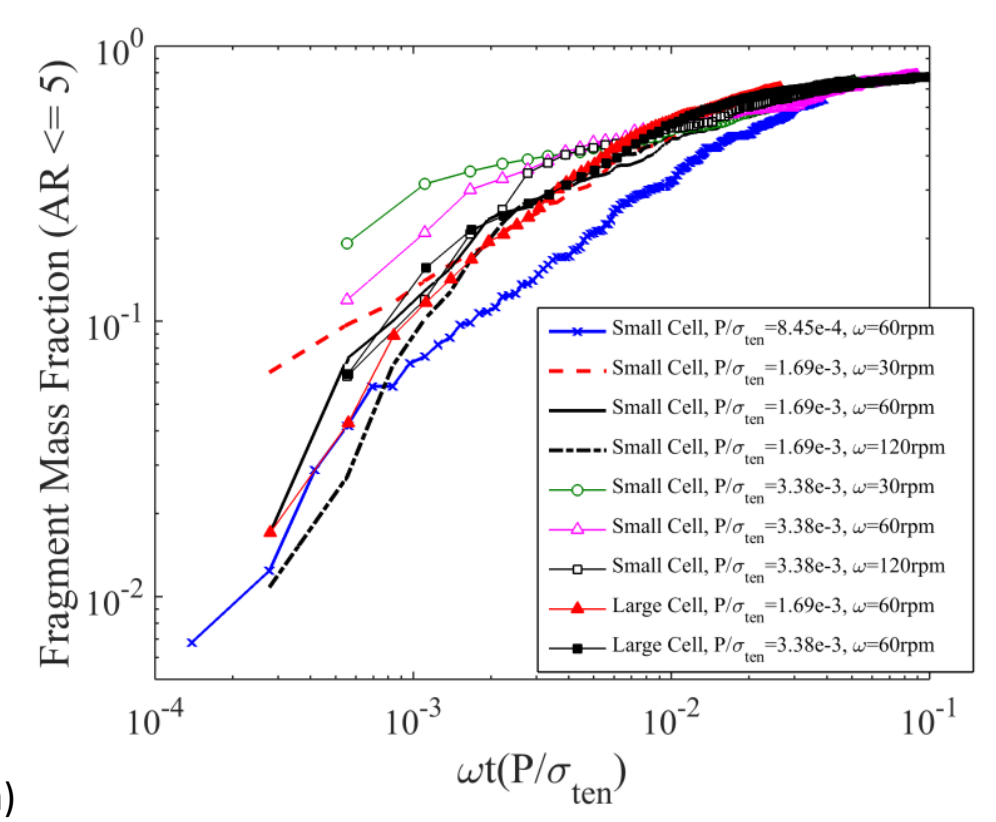

(a)

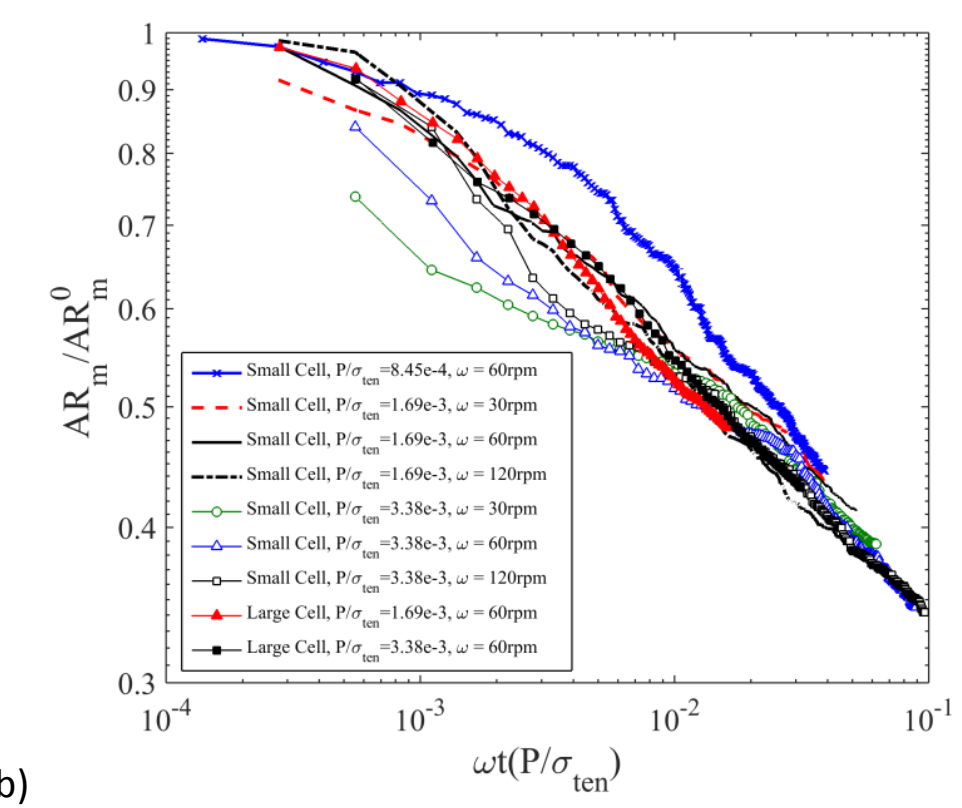

Figure 14 Collapse of particle breakage results with the small and large cells, various impeller angular speeds, and various applied pressures. The unit of $\omega t$ is rad. ( $\left.\mu_{p p}=0.2, \mu_{p w}=0.7\right)$ 


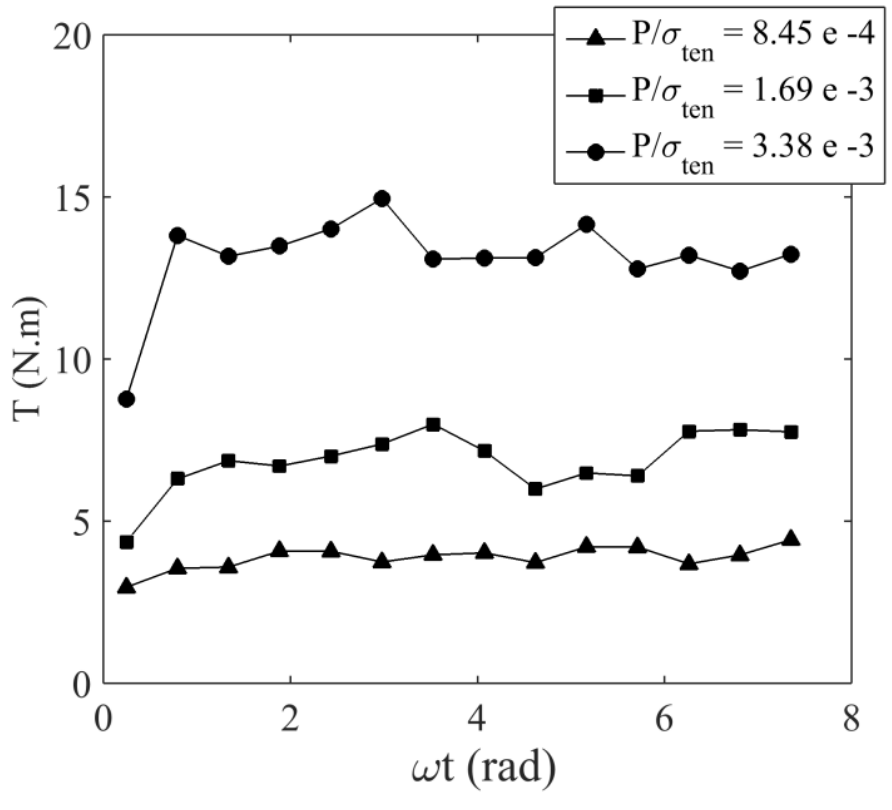

(a)

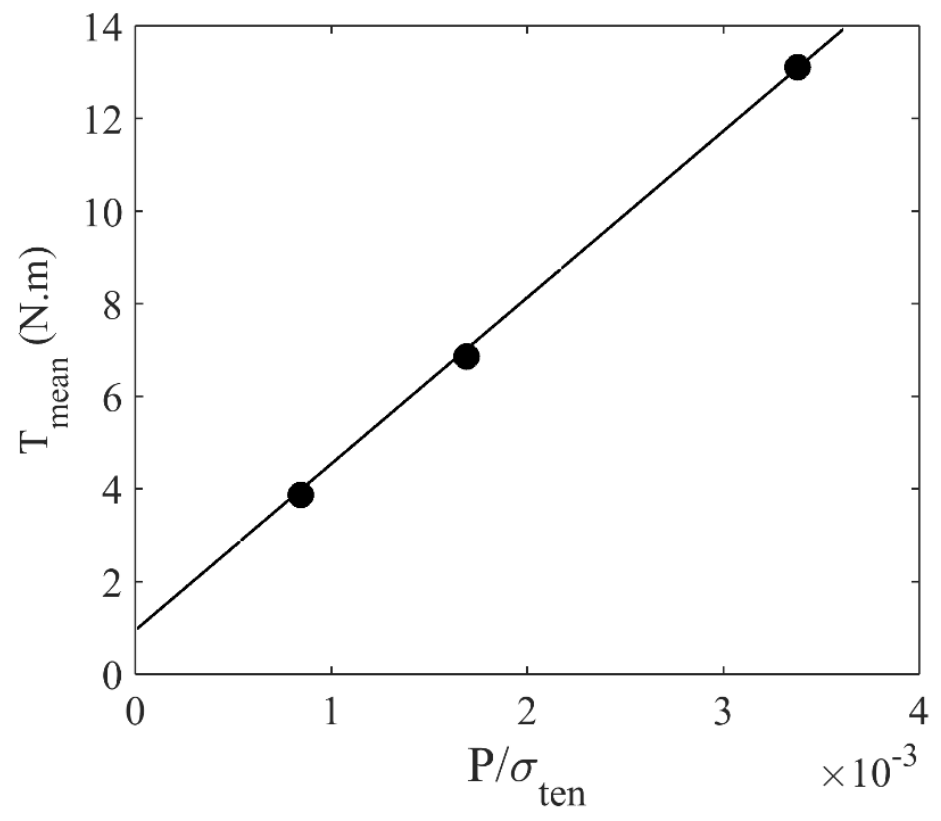

Figure 15 Torque acting on the impeller, $T$, as a function of impeller angular displacement, $\omega t$, for different applied pressures (a) and change of the mean torque, $T_{\text {mean }}$, with the applied pressure, $P / \sigma_{t e n}$. The line in this figure is a linear curve fit. (small cell, $\mu_{p p}=0.2, \mu_{p w}=0.7$, $\omega=60 \mathrm{rpm})$ 


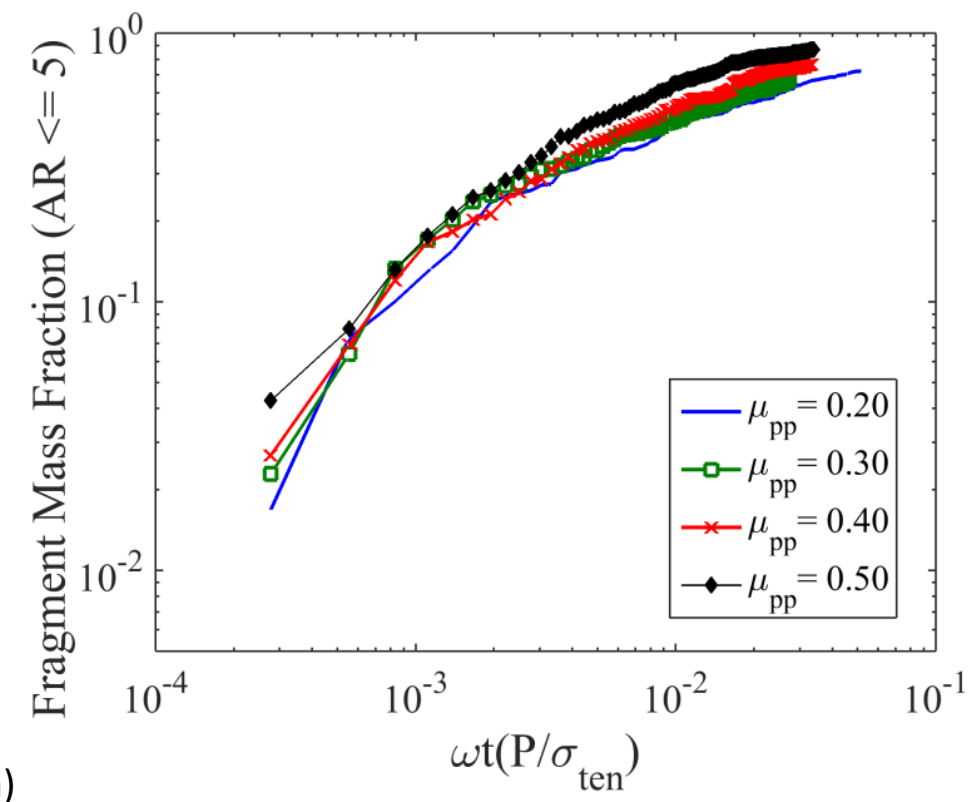

(a)

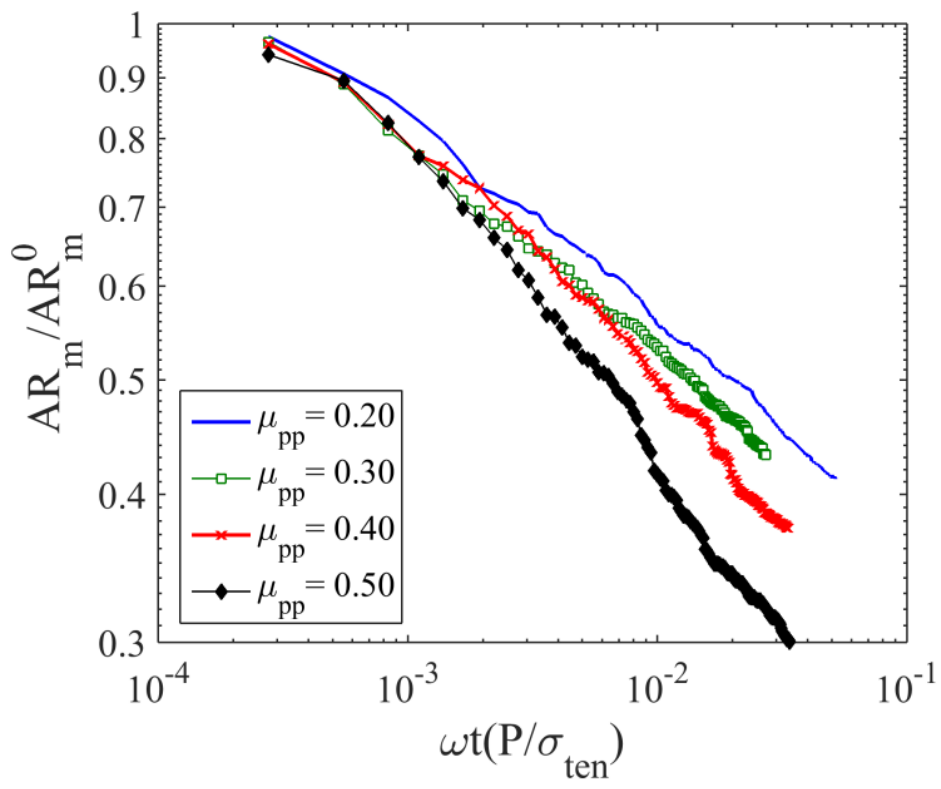

Figure 16 The variation of (a) fragment mass fraction (sieve cut $A R<=5$ ) and (b) normalized mean particle aspect ratio with $\omega t\left(\frac{P}{\sigma_{t e n}}\right)$ for various inter-particle friction coefficients, $\mu_{p p}$. The unit of $\omega t$ is rad. (small cell, $\mu_{p w}=0.7, \omega=60 \mathrm{rpm}, \frac{P}{\sigma_{\text {ten }}}=1.69 \mathrm{e}-3$ ) 


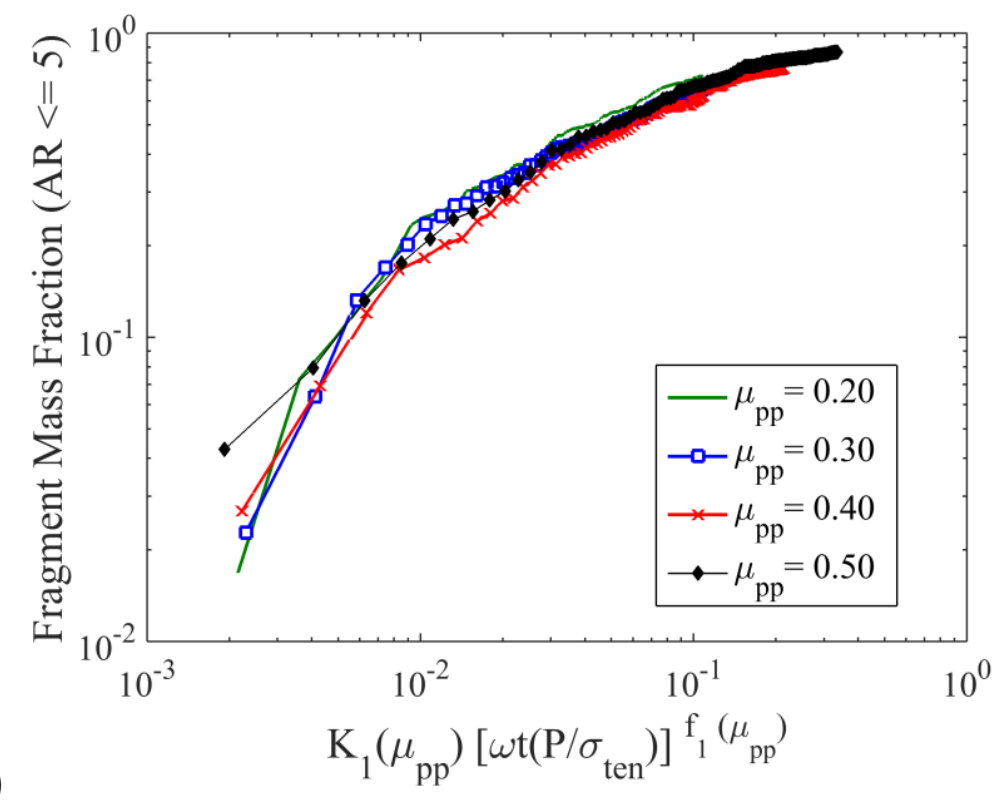

(a)

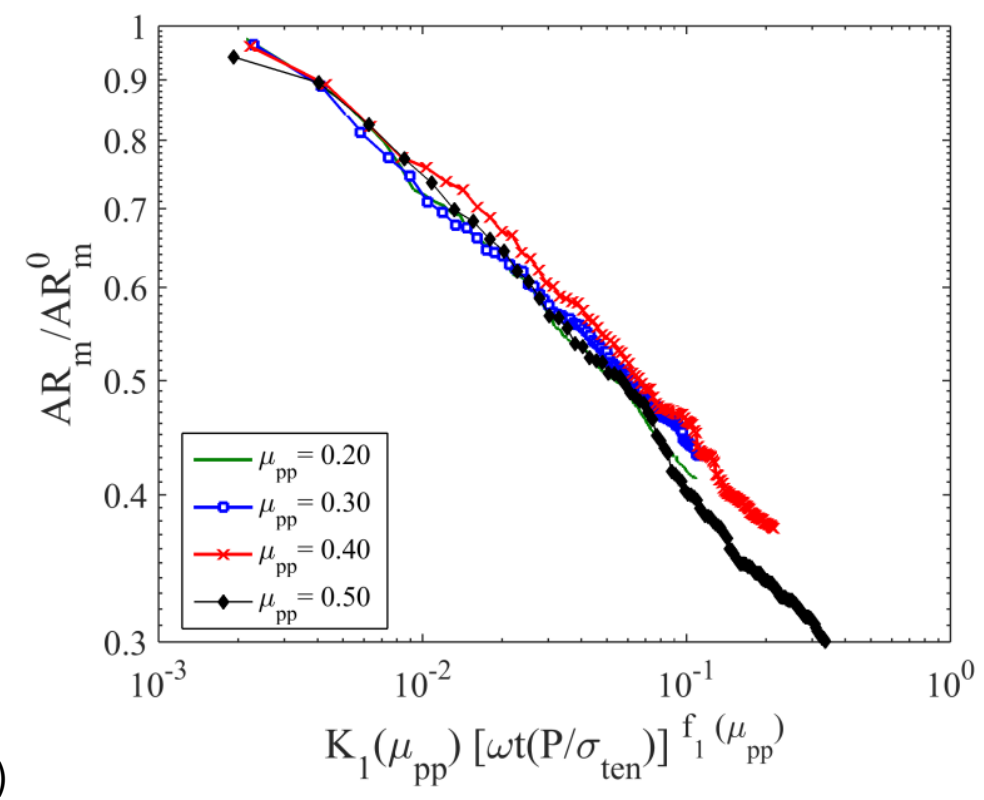

Figure 17 Collapse of particle breakage data with various inter-particle friction coefficients, $\mu_{p p}$. The functions $K_{1}$ and $f_{1}$ are given in the text. The unit of $\omega t$ is rad. (small cell , $\mu_{p w}=0.7, \omega=60$ rpm, $\left.\frac{P}{\sigma_{\text {ten }}}=1.69 \mathrm{e}-3\right)$ 


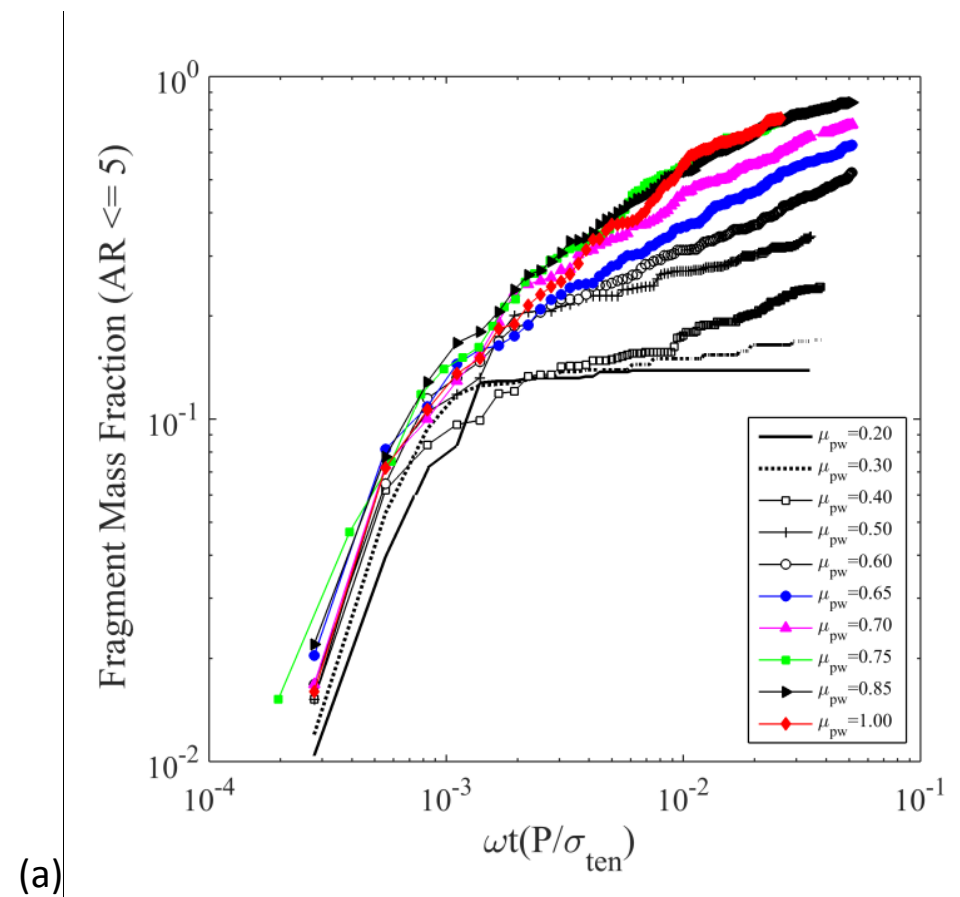

(a)

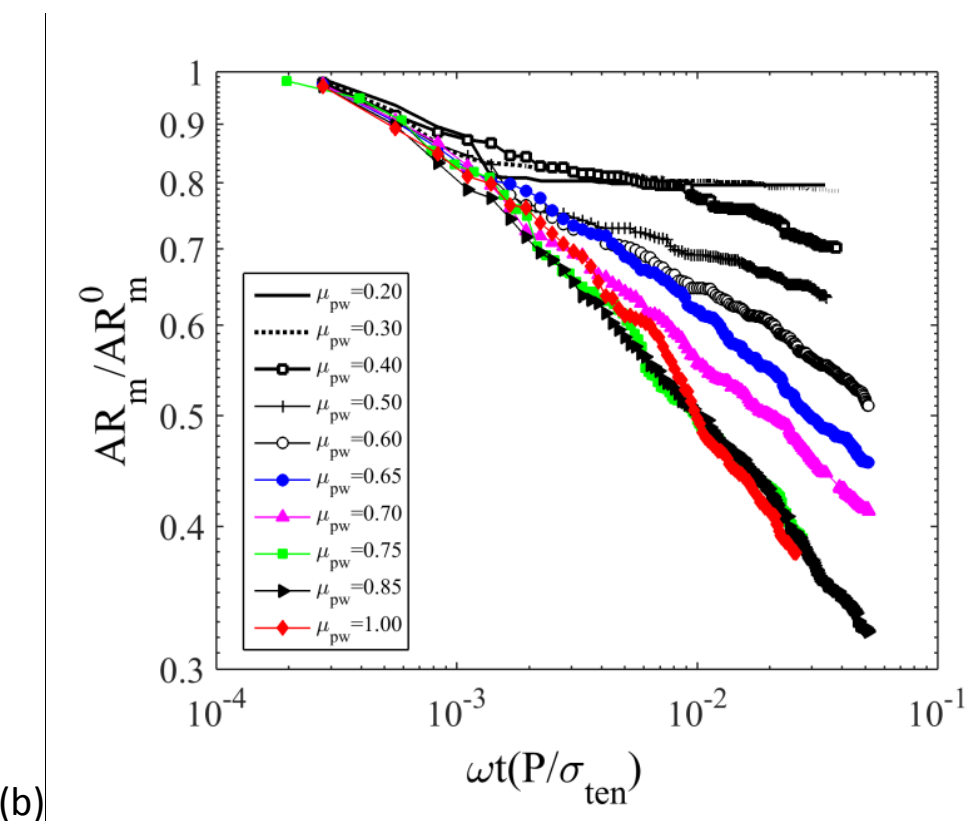

Figure 18 The variation of (a) fragment mass fraction (sieve cut $A R<=5$ ) and (b) normalized mean particle aspect ratio with impeller angular displacement, $\omega t\left(\frac{P}{\sigma_{t e n}}\right)$, for various wallparticle friction coefficients, $\mu_{p w}$. The unit of $\omega t$ is rad. (small cell, $\mu_{p p}=0.2, \omega=60 \mathrm{rpm}, \frac{P}{\sigma_{t e n}}=$ $1.69 \mathrm{e}-3)$ 


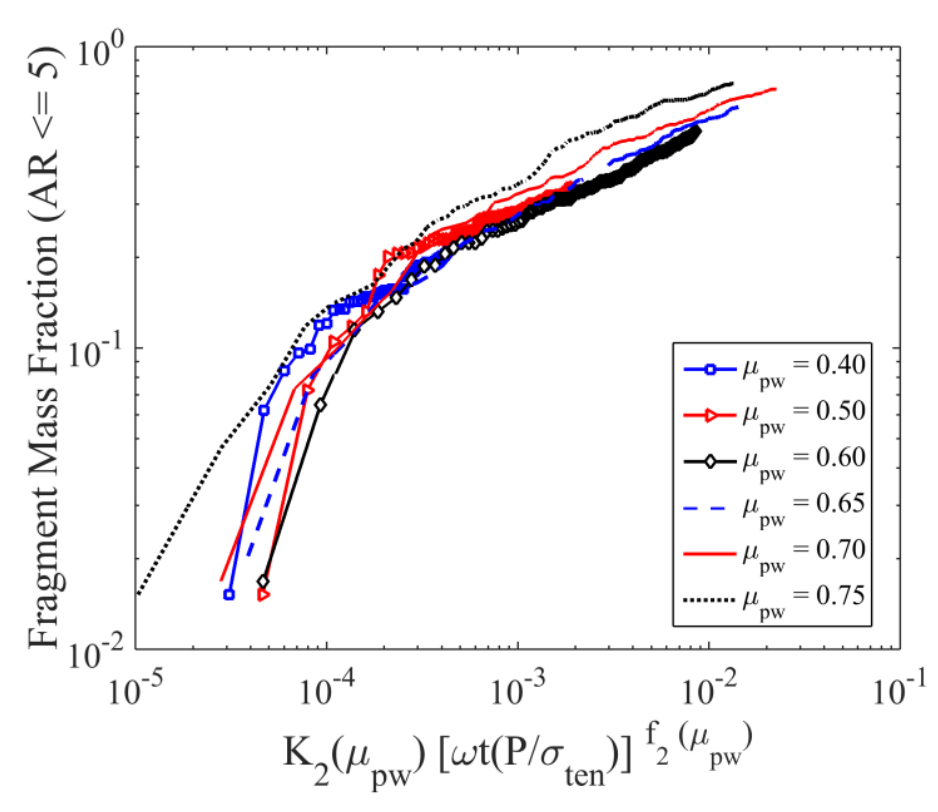

(a)

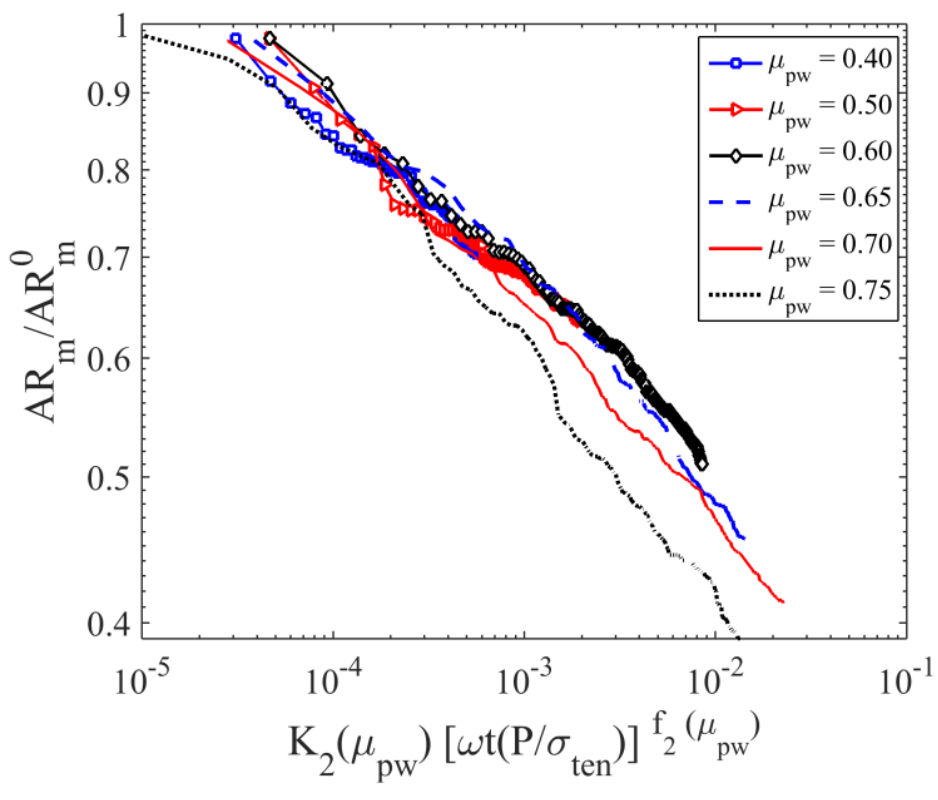

Figure 19 Collapse of particle breakage data with various wall-particle friction coefficients, $\mu_{p w}$. The functions $K_{2}$ and $f_{2}$ are given in the text. The unit of $\omega t$ is rad. (small cell , $\mu_{p p}=0.2, \omega=60$ rpm, $\left.\frac{P}{\sigma_{\text {ten }}}=1.69 \mathrm{e}-3\right)$ 


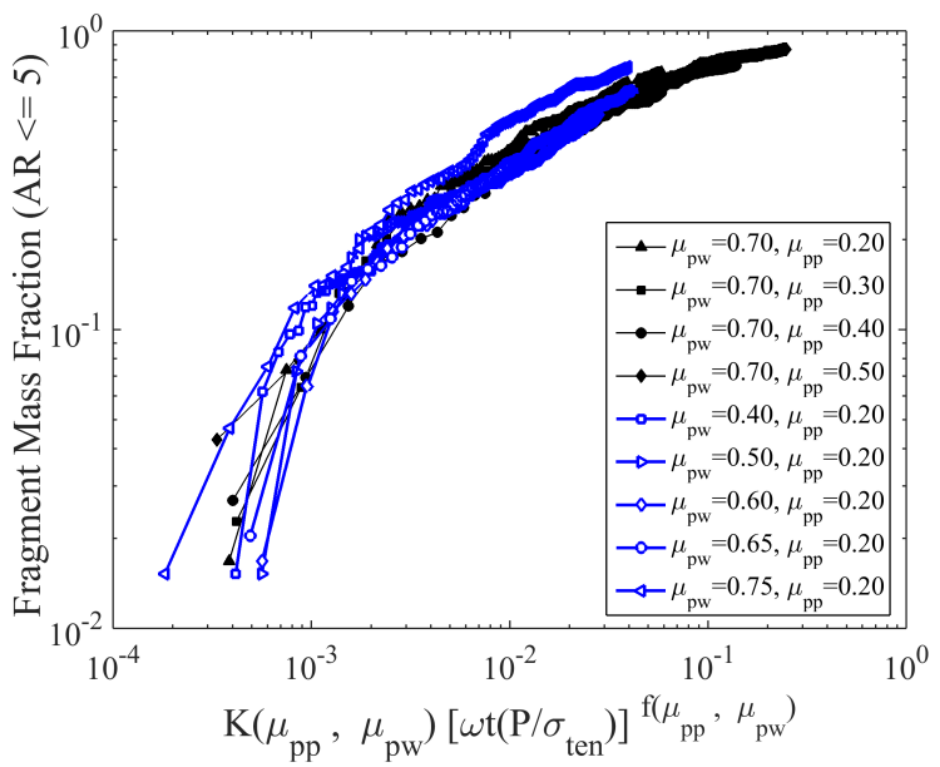

(a)

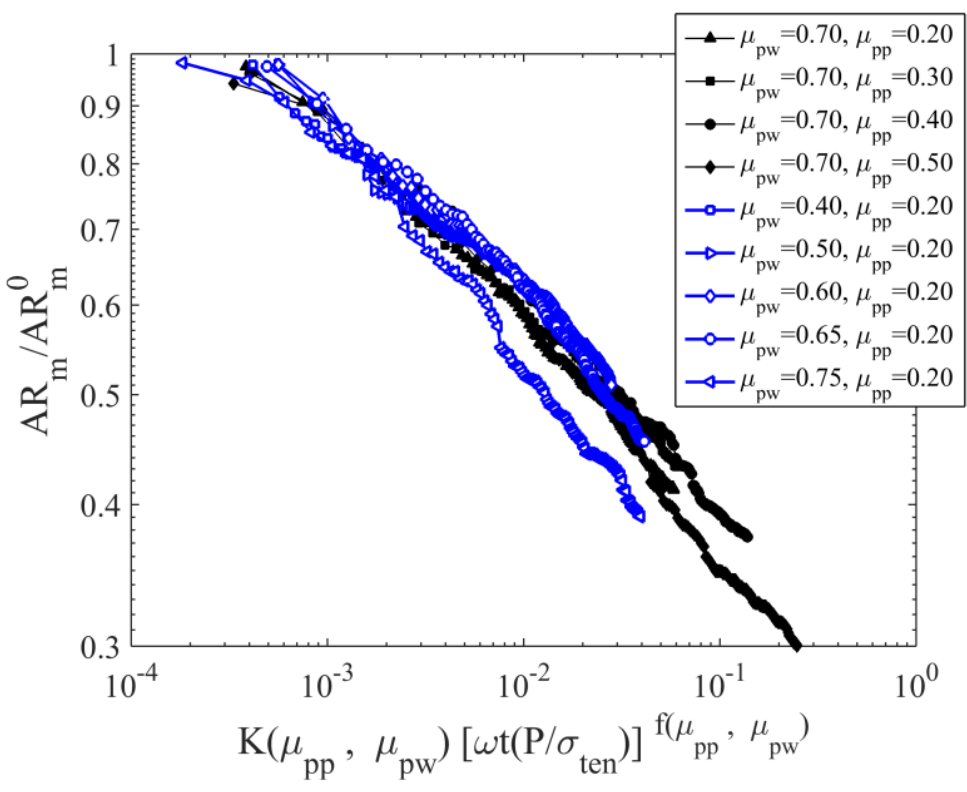

(b)

Figure 20 Collapse of particle breakage data with various inter-particle frictions, $\mu_{p p}$, and various wall-particle friction coefficients, $\mu_{p w}$. The form of the fitting functions $K$ and $f$ are provided in the text. The unit of $\omega t$ is rad. (small cell, $\omega=60 \mathrm{rpm}, \frac{P}{\sigma_{\text {ten }}}=1.69 \mathrm{e}-3$ ) 
Table 1 Parameters used in the uniaxial compression simulations

\begin{tabular}{|c|c|c|c|c|c|c|c|c|c|c|}
\hline & \multicolumn{9}{|c|}{ High Aspect Ratio Particle Properties } & \multirow[b]{2}{*}{\begin{tabular}{|l|}
\multicolumn{1}{|c|}{ Wall } \\
Cylindric \\
al and \\
Flat Wall \\
Young's \\
Modulus \\
$E_{\mathrm{W}}(\mathrm{Pa})$ \\
\end{tabular}} \\
\hline & $\begin{array}{l}\text { Sphere } \\
\text { Diameter } \\
D_{\mathrm{s}}(\mathrm{mm})\end{array}$ & \begin{tabular}{|l|} 
Particle \\
Aspect \\
Ratio \\
$A R$
\end{tabular} & \begin{tabular}{|l|} 
Particle \\
Young's \\
Modulus \\
$E_{\mathrm{p}}(\mathrm{Pa})$ \\
\end{tabular} & \begin{tabular}{|l|} 
Contact \\
Damping \\
Coefficient \\
$\beta_{\mathrm{c}}$
\end{tabular} & \begin{tabular}{|l|} 
Particle \\
Poisson's \\
Ratio \\
$v_{p}$
\end{tabular} & \begin{tabular}{|l|} 
Particle \\
Density \\
$\rho_{p}$ \\
$\left(\mathrm{Kg} / \mathrm{m}^{3}\right)$
\end{tabular} & \begin{tabular}{|l} 
Particle- \\
Particle \\
Friction \\
$\left(\mu_{p p}\right)$
\end{tabular} & $\begin{array}{l}\text { Particle- } \\
\text { Cylindrical } \\
\text { Wall Friction } \\
\left(\mu_{p c}\right)\end{array}$ & \begin{tabular}{|l|} 
Particle- \\
Flat Wall \\
Friction \\
$\left(\mu_{p w}\right)$
\end{tabular} & \\
\hline Base Case & 10 & 8 & $527.6 \mathrm{e} 6$ & $\begin{array}{l}1.59 \text { e-2 } \\
\text { (for } \\
\text { particle- } \\
\text { particle } \\
\text { contact); } \\
3.18 \text { e-2 } \\
\text { (for } \\
\text { particle- } \\
\text { wall } \\
\text { contact); }\end{array}$ & 0.3 & 1570 & 0.624 & 0.35 & 0.4 & 1.0 e 9 \\
\hline $\begin{array}{l}\text { Other } \\
\text { Values } \\
\text { Used }\end{array}$ & NONE & NONE & NONE & NONE & NONE & NONE & NONE & $0.1,0.5$ & $0.1,0.6$ & NONE \\
\hline
\end{tabular}

\begin{tabular}{|c|c|c|c|c|c|c|}
\hline & \multicolumn{6}{|c|}{ Bond Properties } \\
\hline & $\begin{array}{l}\text { Diameter } \\
D_{b}(\mathrm{~mm})\end{array}$ & $\begin{array}{l}\text { Length } \\
l_{b}(\mathrm{~mm})\end{array}$ & $\begin{array}{l}\text { Bond } \\
\text { Young's } \\
\text { Modulus } \\
E_{b}(\mathrm{~Pa})\end{array}$ & $\begin{array}{l}\text { Bond } \\
\text { Damping } \\
\text { Coefficient } \\
\beta_{\mathrm{b}}\end{array}$ & $\begin{array}{l}\text { Bond } \\
\text { Poisson's } \\
\text { Ratio } \\
v_{b}\end{array}$ & $\begin{array}{l}\text { Tensile Strength } \sigma_{\text {ten }} \text { and } \\
\text { Shear Strength } \tau_{s h} \\
(\mathrm{~Pa})\end{array}$ \\
\hline Base Case & 10 & 10 & 527.6 e 6 & 4.20 e-2 & 0.3 & 3.99 e6 \\
\hline $\begin{array}{l}\text { Other } \\
\text { Values } \\
\text { Used }\end{array}$ & NONE & NONE & NONE & $\begin{array}{l}8.87 \text { e-2, } \\
1.41 \text { e-1 }\end{array}$ & NONE & NONE \\
\hline
\end{tabular}


Table 2 Parameters used in the agitated bed simulations

\begin{tabular}{|c|c|c|c|c|c|c|c|c|c|}
\hline & \multirow{2}{*}{\begin{tabular}{|l|}
$\begin{array}{c}\text { Agitation } \\
\text { Cell }\end{array}$ \\
Diameter \\
$D_{\mathrm{c}}(\mathrm{mm})$
\end{tabular}} & \multicolumn{8}{|c|}{ High Aspect Ratio Particle Properties } \\
\hline & & \begin{tabular}{|l|} 
Sphere \\
Diameter \\
$D_{\mathrm{S}}(\mathrm{mm})$
\end{tabular} & $\begin{array}{l}\text { Particle } \\
\text { Aspect } \\
\text { Ratio } \\
A R\end{array}$ & $\begin{array}{l}\text { Particle } \\
\text { Young's } \\
\text { Modulus } \\
E_{\mathrm{p}}(\mathrm{Pa})\end{array}$ & $\begin{array}{l}\text { Contact } \\
\text { damping } \\
\text { coefficient } \\
\beta_{\mathrm{C}}\end{array}$ & \begin{tabular}{|l|} 
Particle \\
Poisson's \\
Ratio \\
$v_{p}$ \\
\end{tabular} & $\begin{array}{l}\text { Particle } \\
\text { Density } \\
\rho_{p} \\
\left(\mathrm{Kg} / \mathrm{m}^{3}\right)\end{array}$ & $\begin{array}{l}\text { Particle-Particle } \\
\text { Friction }\left(\mu_{p p}\right) \text { and } \\
\text { Particle-Cylindrical } \\
\text { Wall Friction }\left(\mu_{p c}\right)\end{array}$ & $\begin{array}{l}\text { Particle-Flat Wall } \\
\text { Friction }\left(\mu_{p w}\right) \text { and } \\
\text { Particle-Blade } \\
\text { Friction }\left(\mu_{p b}\right)\end{array}$ \\
\hline Base Case & $\begin{array}{l}122 \\
\text { (small } \\
\text { cell) }\end{array}$ & 5 & 10 & $2.68 \mathrm{e} 9$ & $\begin{array}{l}1.59 \text { e-2 } \\
\text { (for } \\
\text { particle- } \\
\text { particle } \\
\text { contact); } \\
3.18 \text { e-2 } \\
\text { (for } \\
\text { particle- } \\
\text { wall } \\
\text { contact); }\end{array}$ & 0.3 & 1500 & 0.2 & 0.7 \\
\hline $\begin{array}{l}\text { Other } \\
\text { Values } \\
\text { Used }\end{array}$ & $\begin{array}{l}244 \\
\text { (large } \\
\text { cell) }\end{array}$ & NONE & NONE & NONE & NONE & NONE & NONE & $\begin{array}{l}0,0.05,0.1,0.15 \\
0.3,0.4,0.5\end{array}$ & $\begin{array}{l}0.2,0.3,0.4,0.5 \\
0.6,0.65,0.75 \\
0.85,1.0\end{array}$ \\
\hline
\end{tabular}

\begin{tabular}{|l|l|l|l|l|l|l|}
\hline & \multicolumn{9}{|c|}{ Bond Properties } \\
\cline { 2 - 7 } & $\begin{array}{l}\text { Diameter } \\
D_{b}(\mathrm{~mm})\end{array}$ & $\begin{array}{l}\text { Length } \\
l_{b}(\mathrm{~mm})\end{array}$ & $\begin{array}{l}\text { Bond } \\
\text { Young's } \\
\text { Modulus } \\
E_{b}(\mathrm{~Pa})\end{array}$ & $\begin{array}{l}\text { Bond } \\
\text { Damping } \\
\text { Coefficient } \\
\beta_{\mathrm{b}}\end{array}$ & $\begin{array}{l}\text { Bond } \\
\text { Poisson's } \\
\text { Ratio } \\
v_{b}\end{array}$ & $\begin{array}{l}\text { Tensile Strength } \sigma_{\text {ten }} \text { and } \\
\text { Shear Strength } \tau_{\text {sh }} \\
(\mathrm{Pa})\end{array}$ \\
\hline Base Case & 5 & 5 & $2.68 \mathrm{e} 9$ & $4.2 \mathrm{e}-2$ & 0.3 & $12.3 \mathrm{e} 6$ \\
\hline $\begin{array}{l}\text { Other } \\
\text { Values } \\
\text { Used }\end{array}$ & NONE & NONE & NONE & NONE & NONE & NONE \\
\hline
\end{tabular}




\begin{tabular}{|c|c|c|c|c|c|c|c|c|c|c|}
\hline & \multicolumn{4}{|c|}{ Blade Properties } & \multicolumn{6}{|c|}{ Operating Parameters } \\
\hline & $\begin{array}{l}\text { Blade } \\
\text { Length } \\
L_{\mathrm{bl}} \\
(\mathrm{mm})\end{array}$ & $\begin{array}{l}\text { Blade } \\
\text { Width } \\
W_{\mathrm{bl}} \\
(\mathrm{mm})\end{array}$ & $\begin{array}{l}\text { Blade } \\
\text { Young's } \\
\text { Modulus } \\
E_{\mathrm{bl}}(\mathrm{Pa})\end{array}$ & $\begin{array}{l}\text { Blade } \\
\text { Poisson' } \\
\text { s Ratio } \\
v_{\mathrm{bl}}\end{array}$ & $\begin{array}{l}\text { Number of } \\
\text { Initial } \\
\text { Elongated } \\
\text { Particles }\end{array}$ & $\begin{array}{l}\text { Normalized } \\
\text { Applied } \\
\text { Pressure } \\
P / \sigma_{\text {ten }}\end{array}$ & $\begin{array}{l}\text { Angular } \\
\text { Velocity of } \\
\text { Blades } \\
\omega(\mathrm{rpm})\end{array}$ & $\begin{array}{l}\text { Position } \\
\text { of Blades } \\
\text { from the } \\
\text { Base } \\
h_{\mathrm{bl}}(\mathrm{mm})\end{array}$ & $\begin{array}{l}\text { Number of } \\
\text { Blades }\end{array}$ & $\begin{array}{l}\text { Pitch Angle of } \\
\text { Blades } \\
\theta \text { (degree) }\end{array}$ \\
\hline $\begin{array}{l}\text { Base } \\
\text { Case }\end{array}$ & $\begin{array}{l}61 \\
\text { (small } \\
\text { cell) } \\
\end{array}$ & 10 & $2.68 \mathrm{e} 9$ & 0.3 & 250 & $1.69 \mathrm{e}-3$ & 60 & 15 & 3 & 60 \\
\hline $\begin{array}{l}\text { Other } \\
\text { Values } \\
\text { Used }\end{array}$ & $\begin{array}{l}122 \\
\text { (large } \\
\text { cell) } \\
\end{array}$ & NONE & NONE & NONE & $\begin{array}{l}750 \\
1500\end{array}$ & $\begin{array}{l}\text { 8.45e-4, } \\
3.38 e-3\end{array}$ & $\begin{array}{l}30 \\
120\end{array}$ & NONE & NONE & NONE \\
\hline
\end{tabular}




\section{Graphical Abstract}

This article presents a computational study of the breakage of high aspect ratio particles subject to mechanical agitation using the Discrete Element Method (DEM), in which a particle, represented by a string of bonded spheres, breaks at the center of a bond where the tensile or shear stress exceeds the material strength. The model is validated and used to investigate particle breakage when agitated by rotating blades, which is encountered in a range of pharmaceutical processes. The simulation results show that the breakage rate, that is the rate of particle size reduction (or the rate of fragment mass increase), increases as the applied pressure, impeller rotational speed, particle-particle friction, or particle-equipment friction increases. It is found that the extent of particle breakage is a function of the work performed on the material, and the parameters in this function depend on the particle-particle and particlewall friction coefficients. The large friction coefficients enable the input energy to break the particles more efficiently.

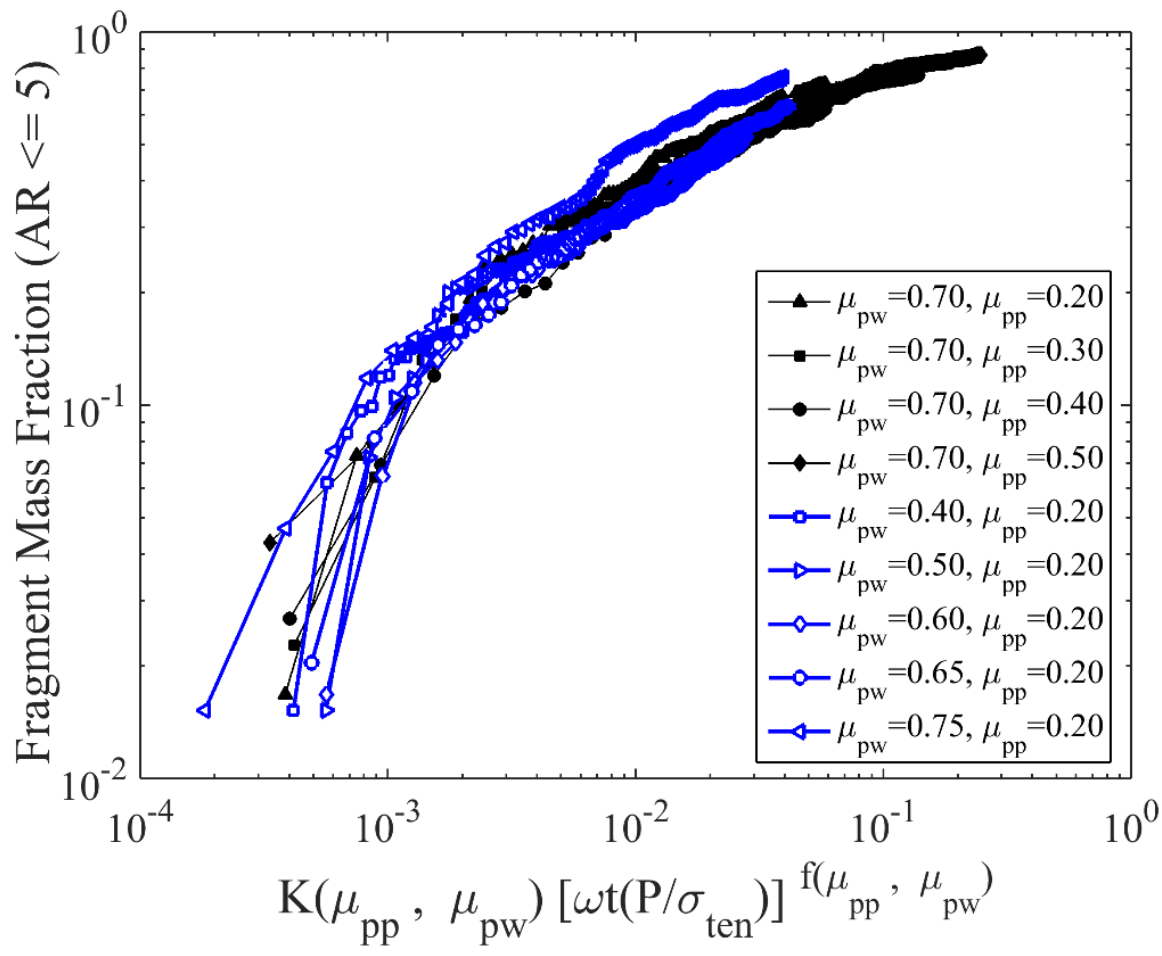

